\title{
A European Respiratory Society technical standard: exhaled biomarkers in lung disease
}

\author{
Ildiko Horváth (task force co-chair) ${ }^{1}$, Peter J. Barnes (task force co-chair) ${ }^{2}$, \\ Stelios Loukides (group chair) ${ }^{3}$, Peter J. Sterk (group chair) ${ }^{4}$, \\ Marieann Högman (group chair) ${ }^{5}$, Anna-Carin Olin (group chair) ${ }^{6}$, \\ Anton Amann ${ }^{7}$, Balazs Antus ${ }^{8}$, Eugenio Baraldi ${ }^{9}$, Andras Bikov ${ }^{10}$, \\ Agnes W. Boots ${ }^{11}$, Lieuwe D. Bos ${ }^{12}$, Paul Brinkman ${ }^{4}$, Caterina Bucca ${ }^{13}$, \\ Giovanna E. Carpagnano ${ }^{14}$, Massimo Corradi ${ }^{15}$, Simona Cristescu ${ }^{16}$, \\ Johan C. de Jongste ${ }^{17}$, Anh-Tuan Dinh-Xuan ${ }^{18}$, Edward Dompeling ${ }^{19}$, \\ Niki Fens ${ }^{4}$, Stephen Fowler ${ }^{20}$, Jens M. Hohlfeld ${ }^{21,22}$, Olaf Holz ${ }^{21}$, \\ Quirijn Jöbsis ${ }^{23}$, Kim Van De Kant ${ }^{19}$, Hugo H. Knobel ${ }^{24}$, Konstantinos Kostikas ${ }^{25}$, \\ Lauri Lehtimäki $^{26}$, Jon 0. Lundberg ${ }^{27}$, Paolo Montuschi ${ }^{28}$, Alain Van Muylem ${ }^{29}$, \\ Giorgio Pennazza ${ }^{30}$, Petra Reinhold ${ }^{31}$, Fabio L.M. Ricciardolo ${ }^{32}$, \\ Philippe Rosias ${ }^{19,33}$, Marco Santonico ${ }^{30}$, Marc P. van der Schee 4 , \\ Frederik-Jan van Schooten ${ }^{11}$, Antonio Spanevello ${ }^{34}$, Thomy Tonia ${ }^{35}$ and \\ Teunis J. Vink ${ }^{24}$
}

@ERSpublications

ERS technical standard: exhaled biomarkers in lung disease http://ow.ly/mAjr309DBOP

Cite this article as: Horváth I, Barnes PJ, Loukides S, et al. A European Respiratory Society technical standard: exhaled biomarkers in lung disease. Eur Respir J 2017; 49: 1600965 [https://doi.org/10.1183/ 13993003.00965-2016].

ABSTRACT Breath tests cover the fraction of nitric oxide in expired gas (FENO), volatile organic compounds (VOCs), variables in exhaled breath condensate (EBC) and other measurements. For EBC and for FENO, official recommendations for standardised procedures are more than 10 years old and there is none for exhaled VOCs and particles. The aim of this document is to provide technical standards and recommendations for sample collection and analytic approaches and to highlight future research priorities in the field. For EBC and FENO, new developments and advances in technology have been evaluated in the current document. This report is not intended to provide clinical guidance on disease diagnosis and management.

Clinicians and researchers with expertise in exhaled biomarkers were invited to participate. Published studies regarding methodology of breath tests were selected, discussed and evaluated in a consensus-based manner by the Task Force members.

Recommendations for standardisation of sampling, analysing and reporting of data and suggestions for research to cover gaps in the evidence have been created and summarised.

Application of breath biomarker measurement in a standardised manner will provide comparable results, thereby facilitating the potential use of these biomarkers in clinical practice.

This article has supplementary material available from erj.ersjournals.com

Received: May 122016 | Accepted after revision: Jan 092017

Support statement: Funding was provided by the European Respiratory Society. Funding information for this article has been deposited with the Crossref Funder Registry

Conflict of interest: T. Tonia acts as a methodologist for the European Respiratory Society. Further disclosures can be found alongside this article at erj.ersjournals.com

Copyright OERS 2017 
Affiliations: ${ }^{1}$ Dept of Pulmonology, National Korányi Institute of Pulmonology, Budapest, Hungary. ${ }^{2}$ National Heart and Lung Institute, Imperial College London, Royal Brompton Hospital, London, UK. ${ }^{3}$ National and Kapodistrian University of Athens, Medical School, Attiko University Hospital, Athens, Greece. ${ }^{4}$ Dept of Respiratory Medicine, Academic Medical Centre, University of Amsterdam, Amsterdam, The Netherlands. ${ }^{5}$ Dept of Medical Sciences, Respiratory, Allergy and Sleep Research, Uppsala University, Uppsala, Sweden. ${ }^{6}$ Occupational and Environmental Medicine, Sahlgrenska Academy and University Hospital, Goteborg, Sweden. ${ }^{7}$ Innsbruck Medical University, Innsbruck, Austria. ${ }^{8}$ Dept of Pathophysiology, National Korányi Institute of Pulmonology, Budapest, Hungary. ${ }^{9}$ Pediatric Pneumonolgy, University of Padova, Padova, Italy. ${ }^{10}$ Dept of Pulmonology, Semmelweis University, Budapest, Hungary. ${ }^{11}$ Dept of Pharmacology and Toxicology, University of Maastricht, Maastricht, The Netherlands. ${ }^{12}$ Intensive Care, Academic Medical Center, University of Amsterdam, Amsterdam, The Netherlands. ${ }^{13}$ Biomedical Sciences and Human Oncology, Universita' di Torino, Turin, Italy. ${ }^{14}$ Dept of Medical and Surgical Sciences, University of Foggia, Foggia, Italy. ${ }^{15}$ University of Parma, Parma, Italy. ${ }^{16}$ Dept of Molecular and Laser Physics, Institute for Molecules and Materials, Radboud University, Nijmegen, The Netherlands. ${ }^{17}$ Dept of Pediatrics/Respiratory Medicine, Erasmus MC-Sophia Childrens' Hospital, Rotterdam, The Netherlands. ${ }^{18}$ Physiology, Paris Descartes University Cochin Hospital, Paris, France. ${ }^{19}$ Dept of Paediatrics/Family Medicine Research School CAPHRI, Maastricht University Medical Centre, Maastricht, The Netherlands. ${ }^{20}$ Respiratory Research Group, University of Manchester Wythenshawe Hospital, Manchester, UK. ${ }^{21}$ Clinical Airway Research, Fraunhofer Institute of Toxicology and Experimental Medicine (ITEM), Hannover, Germany. ${ }^{22}$ Medizinische Hochschule Hannover, Hannover, Germany. ${ }^{23}$ Department of Paediatric Respiratory Medicine, Maastricht University Medical Centre (MUMC+), Maastricht, The Netherlands. ${ }^{24}$ Philips Research, High Tech Campus 11, Eindhoven, The Netherlands. ${ }^{25}$ 2nd Respiratory Medicine Dept, University of Athens Medical School, Athens, Greece. ${ }^{26}$ Medical School, University of Tampere, Tampere, Finland. ${ }^{27}$ Physiology and Pharmacology, Karolinska Institutet, Stockholm, Sweden. ${ }^{28}$ Pharmacology, Catholic University of the Sacred Heart, Rome, Italy. ${ }^{29}$ Hopital Erasme Cliniques Universitaires de Bruxelles, Bruxelles, Belgium. ${ }^{30}$ Faculty of Engineering, University Campus Bio-Medico, Rome, Italy. ${ }^{31}$ Institute of Molecular Pathogenesis, Friedrich Loeffler Institut, Jena, Germany. ${ }^{32}$ Clinic of Respiratory Disease, Dept of Clinical and Biological Sciences, University of Torino, Torino, Italy. ${ }^{33}$ Dept of Pediatrics, Maasland Hospital, Sittard, The Netherlands. ${ }^{34}$ Fondazione Salvatore Maugeri, Tradate, Italy. ${ }^{35}$ European Respiratory Society, Lausanne, Switzerland.

Correspondence: Ildiko Horváth, Dept of Pulmonology, National Korányi Institute of Pulmonology, Piheno ut 1 , Budapest, Hungary. E-mail: ildiko.horvathakoranyi.hu

\section{Introduction}

Volatile organic compounds (VOCs) and other different constituents were identified in exhaled breath decades ago and, from them, the fraction of nitric oxide in expired gas (FENO) paved the way as a potential biomarker. Many volatile and non-volatile components are present in the breath in trace amounts, making their detection a challenging task. Applying highly sensitive technology to analyse exhaled breath enables scientists to evaluate the wide scale of different molecules in these samples. Owing to the variety of sampling methods and analytics, the field developed in a largely unrelated manner in three main domains: exhaled breath condensate (EBC), exhaled VOCs and FENO. A fourth area, that of exhaled particles, arrived later. Official recommendations for standardised procedures are available for EBC and FENO but they are $>10$ years old, and there are currently no official recommendations for exhaled VOCs and particles $[1,2]$. There have been new developments and technological advances in the field of EBC and FENO, and broad experience has been gathered over the last decade; therefore, the current document focuses on these areas. For FENO, the specific aim of the current document is to clarify the terminology, update nasal NO measurement and introduce recommendations for NO dynamic models. Leaders in this scientific area thought it important to summarise current evidence related to sampling methods, measurement standardisation and data interpretation; to highlight gaps in knowledge; and to recommend the technical standards to be used and directions for future research. Although the field of exhaled biomarkers is large, there are common issues in sampling and also in mediator analysis. Therefore, it was felt that a joint effort from experts would be the best way to tackle methodology-related issues by using a wide platform to discuss shared problems and unsolved issues in standardisation, and, at the same time, to provide a framework for more detailed discussion in method-specific smaller groups. Thus, the aim of this document prepared by the Task Force (TF) of the European Respiratory Society (ERS) was to provide recommendations for standardisation of sample collection and, evaluation of different analytic approaches, and to highlight future research priorities in the field of exhaled biomarkers. Where previous guidelines for EBC and FENO exist, areas that were not covered were evaluated and have been dealt with in the current document. The group did not aim to provide guidelines for clinical practice.

\section{Committee composition}

Two co-chairs applied for support for an ERS TF. The co-chairs invited clinicians and researchers to participate in the project on the basis of their expertise in research on one or more areas of exhaled biomarkers. The task was split into four parts and co-chairs were asked from members to take the lead for each part, i.e. EBC, VOCs, FENO and exhaled particles. The participants were asked to join the group most relevant to their expertise. Forming groups on different topics enabled TF members to have more in-depth discussions on the specific areas of different samples. 
Recommendations for technology standards and further research

Each group appraised and summarised the existing evidence and then discussed its relevance to improving standards of sampling and measurement of exhaled breath mediators. They also identified any knowledge gaps. Recommendations for technical standards and research priorities were formulated via discussion and consensus generated, first in each individual group then by the presentation of suggested recommendations at a TF meeting during which different aspects were brought together.

\section{Document development}

To identify relevant literature, the Medline database (assessed through PubMed) was searched using key terms such as "exhaled breath condensate", "exhaled biomarkers", "exhaled volatile organic compounds", "electronic nose", "breath print", "exhaled nitric oxide", "nasal nitric oxide" and "exhaled particles". The database search was concluded in July, 2016. Publications providing evidence for methodological questions were reviewed and used to form methodological recommendations. Only scientific publications in the English language were included.

Drafts sent to the co-chair $(\mathrm{IH})$ by group leaders were merged, edited and circulated among the members for review, feedback and approval. Based on the received comments and criticisms, corrections were made to the manuscript, and then the document was submitted for pre-approval by the ERS as required by its TF operation. This document summarises the current evidence related to exhaled biomarker research and the requirements for standardised sampling and analysis where possible. Of importance, it is not intended to provide clinical guidance on disease diagnosis and management. In areas where evidence-based recommendations could not be provided, a consensus-based opinion of the TF members is expressed and the need for further research on the area is highlighted. The document structure below follows the structure of the four working groups.

\section{Exhaled breath condensate}

The definition of EBC by the previous ERS/American Thoracic Society (ATS) TF is used [1]. Briefly, EBC is obtained by cooling exhaled breath through contact with a cold surface or condenser. Samples are collected as fluid or frozen material and analysed immediately or later for volatile and non-volatile macromolecules.

\section{General aspects of exhaled breath condensate collection}

Condensing equipment

Multiple tools exist to cool exhaled air and collect EBC, ranging from homemade systems to a variety of commercial products [1].

Effect of condenser material: Collection systems have different coating materials, e.g. Teflon, polypropylene, glass, silicone or aluminium. Surface or coating materials have a significant influence on different biomarkers $[1,3-6]$. Thus, the material of the entire collection system including sample vials should be inert or must be standardised for each EBC component of interest.

Efficacy of condensation: EBC collection devices work at different cooling temperatures ranging from zero to below $-20^{\circ} \mathrm{C}$. Pre-cooled devices are sensitive to higher ambient temperatures. The efficacy of condensation mainly depends on: 1) the breath volume passed through the system over time; 2) the condensing surface area; and 3) the temperature gradient between exhaled breath and sampling system. Increasing the condensing surface has been shown to increase EBC volume and the number of biomarkers detected [5]. Different components in EBC are differentially sensitive to cold temperatures, and the concentration of some constituents depends on the condensing temperature $[4,7,8]$. Efficacy is improved by the use of a closed condenser design with breath recirculation, especially in young children [9], or by fractionated sampling to separate EBC originating from proximal and more distal airways [10, 11].

Recommendations for future research: For each $\mathrm{EBC}$ component, the optimal condensing material and method should be defined. Comparative methodological studies on collection system and their efficacy are needed.

Exhaled breath condensate collection procedure

Safety: The EBC collection procedure is noninvasive and only requires tidal breathing. Collection does not modify airway surface conditions, and is safe and without adverse effects, even in young children and adults with severe lung disease [1].

Time of collection versus volume: Previously, subjects were asked to breathe tidally over a defined period of time. This recommendation needs to be revised because this mode of sampling results in a widely variable volume of exhaled breath. Presuming constant condenser conditions, the volume exhaled per time 
(i.e. minute volume) has been identified as the most important factor for $\mathrm{EBC}$ volume collected per time $[12,13]$. Consequently, the volume of exhaled breath, the volume of condensate collected from the exhaled volume and the time of collection have to be reported in order to assess efficacy of EBC collection.

Breathing pattern and lung function: The tidal breathing sampling does not affect lung function [13], but variables in the spontaneous breathing pattern may significantly influence EBC collection and composition [14]. Low airflows are advantageous because the collection becomes increasingly inefficient with increasing expiratory flow rates [13]. Hence, it is advised that subjects refrain from exercise for at least 1 hour preceding EBC collection [15]. Slow breathing cycles, i.e. quiet tidal breathing, are recommended because low tidal volumes and high dead-space ventilation in relation to alveolar ventilation lead to EBC samples that mainly derive from conducting airways rather than from peripheral ones. Different origins may remarkably affect EBC composition, and a larger proportion of dead-space ventilation contributes to EBC dilution (by condensed water) and to a greater influence of ambient (inspired) air [16].

Mouth versus nose breathing: Significant differences in EBC composition have been demonstrated between mouth and nose breathing, e.g. with respect to exhaled biomarkers [17, 18]. When mouth breathing is performed, the use of a nose clip is advised because it: 1) prevents inhalation of air through the nose and, therefore, contamination with possible biomarkers from the nasal epithelium; 2) prevents leakage from lower airways via the nose; and 3) prevents mixing of nasal and bronchial air. Salivary contamination should be limited by periodic swallowing. Monitoring by amylase measurements is still controversial. Validation by sufficiently sensitive amylase assays is needed. Microbial activity in the oropharyngeal tract significantly contributes to the concentration of nitrogen oxides in EBC, and may be prevented by mouth rinsing, e.g. with chlorhexidine [19].

Environmental contamination: Important confounding factors may derive from outdoor or indoor ambient air. Possible mechanisms are as follows: 1) ambient air can directly contribute to EBC composition; 2) inhaled mediators can react with substances in $\mathrm{EBC}$; and 3) inhaled mediators can give rise to inflammatory or immunological responses in the airways, which in turn alter EBC composition. This has been shown exemplarily for keratins, proteins and $\mathrm{H}_{2} \mathrm{O}_{2}[20,21]$. To avoid any contamination of EBC from undefined environmental conditions, it is highly recommended that a suitable filter be adapted on the inspiratory valve. Cleaning procedures may also influence biomarker concentrations [1]. Therefore, a careful assessment of any potential confounding arising from cleaning material should be carried out. The cleaning routine used in lung function testing and nebulisers when used in hospitals are described in detail in the relevant guidelines, but they cannot be used as direct evidence for condenser cleaning [22, 23].

Ambient conditions: Ambient temperature and relative humidity may contribute to the variability of EBC results, as shown for $\mathrm{pH}$ [24]. When EBC collection is implemented in field studies, it should be taken into account that breath temperature can significantly change between winter and summer, which will influence the temperature gradient between exhaled breath and the collecting system [16].

Recommendations for future research: Define exhaled volume for EBC collection and report time of collection and volume of EBC obtained, or define time for EBC collection and report the other two variables in parallel. Report: collection temperature and condenser material, characteristics of the breathing pattern, prevention of salivary and environmental contamination, cleaning procedures, and ambient conditions. The influence of these factors needs to be evaluated in further studies.

\section{Storage and processing of exhaled breath condensate samples}

EBC also contains unstable volatiles: during and immediately after collection, volatile substances can be released (evaporation), and EBC composition can change owing to ongoing biochemical processes. For example, storage for only 1 hour at room temperature causes a significant decrease in the partial pressure of $\mathrm{CO}_{2}$ and increases $\mathrm{EBC} \mathrm{pH}$ [13]. Also, data on the stability of $\mathrm{H}_{2} \mathrm{O}_{2}$ in frozen $\mathrm{EBC}$ samples are conflicting and range from 2 days to 2 months. Thus, measurements of at least $\mathrm{pH}$ and $\mathrm{H}_{2} \mathrm{O}_{2}$ have to be performed in real time or immediately after collection without freezing or storing EBC [14].

Standardisation of exhaled breath condensate $\mathrm{pH}$ measurement: Different lines of data suggest that the most important confounder of $\mathrm{pH}$ measurement in $\mathrm{EBC}$ is the presence of $\mathrm{CO}_{2}$ in the samples. Standardisation of $\mathrm{pH}$ measurements in $\mathrm{EBC}$ requires the elimination of the confounding effect of $\mathrm{CO}_{2}$. In one approach, $\mathrm{EBC} \mathrm{pH}$ is measured after removing $\mathrm{CO}_{2}$ from the sample by de-gassing (syn. deaeration or degasification), using an inert gas such as argon. Importantly, de-aeration cannot completely eliminate $\mathrm{CO}_{2}$ from $\mathrm{EBC}$ samples. In an alternative approach, rather than attempting to remove $\mathrm{CO}_{2}$ from $\mathrm{EBC}$, samples are instead sequentially loaded with $\mathrm{CO}_{2}$ gas. At regular time points during the $\mathrm{CO}_{2}$ loading procedure, aliquots are taken for simultaneous $\mathrm{pH}$ and carbon dioxide tension $\left(\mathrm{PCO}_{2}\right)$ measurements by means of a blood gas analyser. By plotting several $\mathrm{pH} / \mathrm{PCO}_{2}$ value pairs for each sample, $\mathrm{EBC} \mathrm{pH}$ can be easily determined for any given $\mathrm{PCO}_{2}$ value using regression analysis. This method yields highly reproducible EBC $\mathrm{pH}$ values at the 
normal alveolar $\mathrm{PCO}_{2}$ of $5.33 \mathrm{kPa}$ [25-27]. Some researchers argue against artificial manipulation of EBC; however, they address only deaeration, not standardisation by $\mathrm{CO}_{2}$ loading [16, 25-27]. Regarding deaeration, it is still unknown how many volatiles besides $\mathrm{CO}_{2}$ are removed while bubbling gas through an EBC specimen, and how the complexity of EBC is changed by this procedure [28]. There is also no standardised protocol for de-gassing so far. It has been demonstrated that different de-gassing procedures (bubbling versus surface delivery) with changing durations significantly influence both losses of EBC volume and concentrations of $\mathrm{EBC}$ components [29]. On the contrary, $\mathrm{CO}_{2}$ loading has been shown to provide the least variability observed so far in $\mathrm{EBC} \mathrm{pH}$ measurement [26]. There is an approximate two order difference in the logarithmic scale of $\mathrm{pH}$ depending on the method used for standardisation, i.e. $\mathrm{pH}$ readings of de-gassed samples with $\mathrm{CO}_{2}$ concentration close to zero versus $\mathrm{pH}$ readings at a standardised $\mathrm{CO}_{2}$ concentration at a $\mathrm{CO}_{2}$ level of $5.33 \mathrm{kPa}$ (physiological alveolar $\mathrm{CO}_{2}$ partial pressure) as determined by regression analysis in $\mathrm{CO}_{2}$-loaded samples.

Storage (temperature, material, duration): If EBC samples need to be stored, conservation should be performed immediately after collection (in order to avoid any errors by evaporation of volatile components or by ongoing biochemical processes). Storage material should be inert, as recommended for EBC collection materials [6]. Recent suggestions focus on immediate freezing using dry ice and storage at $-80^{\circ} \mathrm{C}$ until analysed [4]. Freeze-drying (lyophilisation) of EBC has been proposed as a promising method to concentrate the sample [29]. However, at present, very little is known about the reliability and reproducibility of results if freeze-drying is applied to EBC samples [30]. For most EBC components there is still a lack of knowledge of how long they remain stable during storage. No relationship was found between the concentration of EBC cytokines and storage times of up to 1 year in samples stored at $-80^{\circ} \mathrm{C}$ [31]. No significant loss of isoprostanes was found in a 2 -week stability study at $-80^{\circ} \mathrm{C}$ [32]. In contrast, leukotrienes undergo significant degradation within a few weeks or months [33].

Recommendations for future research: The time between collection and analysis should be as short as possible, and the stability of each biomarker should be checked during the storage period. If sample additives such as assay reagents and protease inhibitors are used, this should be clearly described. Routine deaeration of EBC before $\mathrm{pH}$ measurement can no longer be recommended. Because of the large difference in observed values between the different methods for measuring $\mathrm{pH}$, the same methodology should be applied in longitudinal and multicentre studies. Future research is needed to address the optimal choice for $\mathrm{EBC} \mathrm{pH}$ measurement. In the meantime, $\mathrm{pH}$ measurements should be performed twice, i.e. before and after processing $\mathrm{EBC}$, and both results reported together with the processing technique, or $\mathrm{pH}$ readings at a standardised $\mathrm{CO}_{2}$ concentration at a $\mathrm{CO}_{2}$ level of $5.33 \mathrm{kPa}$ should be provided. The effects of storage time and storage conditions on the stability of different components need to be carefully evaluated for each substance. Further studies providing standardised processing protocols are warranted.

\section{Interpretation of exhaled breath condensate data}

One of the key problems is that most of the concentrations measured in EBC have been published in the units they were measured in as raw data in the liquid sample, e.g. $\mathrm{pg} \cdot \mathrm{mL}^{-1}, \mathrm{nmol} \cdot \mathrm{mL}^{-1}$ or $\mu \mathrm{mol} \cdot \mathrm{L}^{-1}$. In fact, $1 \mathrm{~mL}$ EBC cannot be considered a standardised biological specimen at all, because the percentage of condensed liquid of the exhaled volume is not constant for each collection process. Instead, one has to be aware that different collection systems and procedures will generate differently diluted condensates with variable characteristics, despite similar concentrations in exhaled breath.

How to standardise the level of a biomarker assessed in exhaled breath condensate

Dilution by water: The degree of dilution of EBC by condensed water mainly depends on: 1) the efficacy of the collection system; and 2) the individual breathing characteristics. The use of different dilution factors (e.g. urea, conductivity or total cations) [34] or calculating the analysed mediator in relation to the conductivity of the given EBC sample [35] have been proposed for better standardisation with a very wide range of reported physiological dilution rates (between 1000 and 48000).

Exhaled breath volume per time: Owing to their solubility or reactivity, gaseous components can be assessed in the liquid EBC sample. For volatile substances, it is the quantity that has been exhaled in relation to the exhaled volume per time that is of interest [36]. This recalculation is possible when taking into account the exhaled volume, the time of EBC collection and the volume of collected EBC. When this approach was applied to volatiles and even non-volatiles in EBC, the quantities of lactate exhaled per minute and quantities of $\mathrm{H}_{2} \mathrm{O}_{2}$ or leukotriene $\mathrm{B} 4$ exhaled per $100 \mathrm{~L}$ of exhaled breath were less variable compared to concentrations assessed per millilitre of $\mathrm{EBC}[16,37]$.

Particle-associated EBC components: The presence of non-volatile molecules in EBC (proteins, cytokines, etc.) is most likely linked to the exhalation of micro-droplets, i.e. aerosols or particles. Aerosol formation can be simply explained by the bronchiole fluid film burst model [38]. This hypothesis states that aerosols 
are formed by a process of respiratory fluid film or bubble bursting during the reopening of respiratory bronchioles by inhalation and the subsequent fragmentation of droplet aerosols that are drawn into the alveoli until emission during the next exhalation. An increasing number of publications support this model $[39,40]$. Emission of particles by exhalation is mainly dependent on individual lung physiology and respiratory pattern [40]. Consequently, the quantity of droplet-associated EBC components differs significantly between subjects, is not normally distributed and presents significant inter-subject variability that exceeds variations caused by airway diseases $[16,40]$. To overcome this problem, normalisation of non-volatile EBC components in relation to the emission rate of exhaled particles has been proposed. This approach requires on-line monitoring of exhaled particles in future EBC studies [41].

Recommendations for future research: Any analysed concentration in the liquid condensate underlies multiple methodological sources of variability given by the collection process. To reduce the confounding influence of dilution, the concentration of EBC components exhaled per $100 \mathrm{~L}$ of exhaled breath and/or per minute should be recalculated. Further concepts of interpretation are urgently needed that take into account the exhaled particles as well.

\section{Reproducibility, dilution factor and concentration of samples}

Three important points drive the reproducibility issue: 1) the lack of standardisation of EBC collection methods and validation of biomarker measurement across different laboratories; 2) the fact that many biomarkers have been detected near the lower limits of the assay; and 3) the absence of a valid dilution factor and/or concentration method [5, 42, 43]. Regarding the dilution factor, it has not yet been convincingly demonstrated that better reproducibility can be achieved by normalising EBC data with a dilution factor.

Recommendations for future research: Give details of intra-assay and inter-assay reproducibility measurements carried out using EBC samples by using appropriate means of evaluation. Specify the lower limit of detection. Difficulties related to the sensitivity of detection methods need to be solved, appropriate statistical approaches (i.e. non-parametric tests) should be used and the proportion of samples below the detection limit must be reported.

\section{Age and sex, food and drink}

Some differences depending on sex and age have been detected in various EBC biomarkers [26, 44], although data are conflicting. Children adequately perform EBC collection with the same technique used in adults [11].

Food and drink might affect the levels of directly related mediators. For example, food and beverages containing oxidants, NO-related products or affecting acidity might influence any markers relating to NO, $\mathrm{pH}$ or oxidative stress $[45,46]$. The time between food intake and EBC collection can significantly influence EBC composition [20].

Recommendations for future research: Age and sex should be recorded and taken into account as confounding factors in any EBC assessment. When measuring mediators known to be affected by certain drinks or foods, it is advisable that subjects avoid these for at least 8 hours prior to measurement. EBC collection systems suitable for infants and preschool children need to be developed.

\section{Diurnal variability}

Diurnal variability has been demonstrated for $\mathrm{EBC} \mathrm{H}_{2} \mathrm{O}_{2}$ level in healthy subjects and patients with chronic obstructive pulmonary disease (COPD) [47, 48].

Recommendations for future research: In order to consider the potential role of diurnal variability, sampling should be planned for the same time of day. The diurnal variability for mediators in EBC should be investigated.

\section{Ventilated patients}

Numerous studies have been performed using EBC in association with mechanical ventilation. However, EBC collection in ventilated subjects is influenced by multiple factors, such as artificial humidification and ventilator mode [49].

Recommendations for future research: $\mathrm{EBC}$ analysis may be used to monitor lung inflammation and injury in ventilated patients. Effects of underlying mechanisms should be assessed.

\section{Systemic diseases}

The number of studies investigating EBC mediators in systemic diseases has recently increased. Possible new markers have been proposed for systemic diseases involving the lungs, such as 8-isoprostane, 
prostaglandin $\mathrm{E}_{2}$ and nitrates for cystic fibrosis; interleukin (IL)-8 for systemic lupus erythematosus; IL-4, cysteinyl leukotrienes and 8-isoprostane for systemic sclerosis; and $\mathrm{H}_{2} \mathrm{O}_{2}$ in uraemia [50, 51].

Recommendations for future research: Further investigate the role of EBC components in systemic diseases and compare with already established parameters of disease assessment.

\section{Smoking}

Different inflammatory and oxidative stress EBC biomarkers including $\mathrm{H}_{2} \mathrm{O}_{2}$ are sensitive to tobacco smoking. New "omic" markers have recently been investigated in smokers using genomic, proteomic, metabolomic and epigenomic approaches [52, 53]. A few EBC studies on IL-4, IL-5, IL-10, IL-17, $\gamma$-interferon and 8-isoprostane in water-pipe smokers are available [54].

Recommendations for future research: Consider studies of smoking cessation and the use of electronic nicotine delivery systems and their effects on different mediators.

\section{Medications}

Several studies have investigated the effect of medication on EBC constituents in a systematic manner [55-59]; however, a number of these studies lack a long-term controlled design.

Recommendations for future research: Consider the potential effect of medication. Plan to perform longitudinal controlled studies to evaluate the possible effects and/or the use of mediators as a tool of guided treatment strategy.

\section{Reference values}

Standardising EBC evaluation requires the establishment of reference values in healthy subjects. Some of the most widely studied biomarkers that have data published by independent research groups for the establishment of reference values are $\mathrm{H}_{2} \mathrm{O}_{2}, 8$-isoprostane, adenosine, $\mathrm{pH}$ and leukotrienes [1, 60, 61]. However, further standardisation of collection and measurement methods is required.

\section{Exhaled breath condensate mediators in different diseases}

There are a large number of studies on EBC mediators in different respiratory and other diseases $[1,9,48$, 62-82]. More details on this area are provided in supplement 1.

Recommendations for future research: Further clinical studies are needed in EBC, including the establishment of reference values.

\section{Conclusions for exhaled breath condensates}

It is unlikely that "one standardisation" will fulfil the requirements of the different substances measurable as potential biomarkers in EBC. Likely, different steps of standardisation need to be adjusted for EBC components of interest. The relevance of future EBC publications depends not only on a scientific pro/con description of specific biomarker findings in a certain group of subjects, but also on the inclusion of a systematic and meticulous description of the methods and techniques used to collect, preserve and analyse EBC. Enabling technologies facilitates the use of this human sample that is known not only for its potential, but also for the difficulty in handling it $[83,84]$.

\section{Exhaled volatile organic compounds}

Molecular analysis of exhaled breath volatiles (breathomics) provides a noninvasive tool for exploring the human body, including the lung and other organs [85-89]. High-throughput omics technologies based on unbiased systems biology approaches, including transcriptomics, proteomics, lipidomics and metabolomics, are increasingly used for phenotype discovery and have potential as "point-of-care" diagnostic tools [90-96].

VOCs arise in exhaled breath, urine, blood, saliva and faeces, and are also emitted by skin [97]. VOCs can have an endogenous metabolic origin either related or not to previous exogenous exposures (smoking, medication, food, etc.) [98] or can originate from bacteria in the gut or airways. Exhaled VOCs can also include any VOCs inhaled from the environment, including the sampling device. The biochemical background is only known for a few endogenous VOCs, such as isoprene and acetone. The concentration of exhaled VOCs is influenced by the compound-specific blood:gas partition coefficient [99], cardiac output and alveolar minute volume [100]. Furthermore, ingestion of precursors (e.g. valproate or ${ }^{13} \mathrm{C}$-dextramethorphan) can result in exhalation of their volatile metabolites (e.g. 3-heptanone or ${ }^{13} \mathrm{CO}_{2}$ ). This is important in enzyme-specific breath tests [101]. 


\section{Sampling}

The choice of the methodology depends on the application. Issues related to exhaled breath sampling include correction for ambient inspired volatiles, type of sampling (total versus alveolar breath), sampling duration (single-breath versus fixed-time or fixed-volume breathing), effect of expiratory flow and breath hold, type of collecting materials, VOC recovery, sample pretreatment, effect of humidity, food/medications, exercise, smoking and co-morbidities [85, 102, 103].

All sampling methods require standardisation and external validation in multicentre studies. The International Association of Breath Research and a consortium of breath-researchers are pursuing this and aim to develop an open-source standardised methodology for breath sampling that currently awaits validation in clinical trials (details are available at www.breathe-free.org). Because the measurement of exhaled volatiles is in its discovery phase, the sharing of knowledge and experience is very valuable. Therefore, as a breath community, we are expressing our disagreement with patenting biomarker patterns (or signal patterns) and sampling methods of exhaled breath because it slows down the innovation cycle.

\section{Sampling methods}

Sampling devices vary between young children, adults and severely ill patients.

Two complimentary approaches are advocated to reduce the effect of environmental VOCs. First, ambient VOC concentration can be subtracted from exhaled VOC concentrations (alveolar gradient) [102], although this does not account for interactions with the patient [104]. Second, inhalation/exhalation filters can be used for breathing (relatively) VOC-free air before sampling (wash-in phase) [105]. However, alveolar gradients can be affected by several pulmonary kinetic factors [106]. In addition, set-ups designed to completely reduce background contamination have been unsuccessful [102].

Exhaled breath can be collected by mixed expiratory sampling (total breath including anatomical dead-space air) [105] or alveolar sampling (obtained as enriched alveolar breath by expired $\mathrm{CO}_{2}$ triggers or by discarding the first part of exhalation corresponding to dead-space) [107]. The choice of focusing on VOCs derived from alveoli and/or conducting airways depends on the disease of interest. However, when sampling through the nose or mouth, the interaction of VOCs from alveolar air with the intra- and extrapulmonary airway wall cannot be avoided. Nevertheless, comparison of both methods might help to identify the VOC source within the respiratory compartments. Selective sampling of the alveolar compartment can reduce oral contaminant concentrations [106], but is technically more demanding [108].

Breath sampling during a fixed time can reduce variations in breath-to-breath volatile concentrations reported in single-breath analysis $[106,109]$. Alternatively, breath sampling from a predefined fixed volume is also used. Recently, a new method of integrating real-time breath sampling with spirometry was technically and medically validated. Physico-chemical properties of individual volatiles and collecting materials affect relative VOC recoveries [110]. Ideally, collection devices should be inert and/or disposable, given that many materials and cleaning agents emit VOCs with a high risk of carry-over effects even under stringent conditions [108]. As an alternative to single use, stringent cleaning regimes for collection devices (e.g. Tedlar or Mylar bags) by repeated washings with ultra-pure nitrogen have been shown to provide acceptable repeatability [111, 112]. It should be noted, however, that remaining or variable VOC contributions by Tedlar bags are difficult to recognise using cross-reactive sensors in electronic noses (e-noses).

\section{Conditioning volatile organic compound samples}

VOCs can either be analysed directly (real time) or undergo several pretreatment steps. VOC concentrations are generally in the parts per billion to parts per trillion (nM to pM) range [113]. For this reason, pre-concentrations of breath samples by adsorption onto sorbent traps or coated fibres may be required to provide a sufficient signal on the used analyser. VOC adsorption onto sorbent traps, the most common sample pretreatment procedure, also increases sample stability [114]. However, different sorbents absorb VOCs selectively. This enables focus to be directed to target volatiles, but reduces molecular information. The detection limits of different analysers vary widely, but new developments are bringing high-sensitivity analytical technologies into marker detection that are capable of detecting volatiles in the low parts per billion range, bringing the analysis of exhaled VOCs closer.

The response of some types of sensor is affected by water vapour; this is a critical issue for e-nose research on exhaled samples $[103,115]$. Different approaches have been used to reduce the effect of ambient/sample humidity on breath VOC analysis, including the use of silica gel [105] and potassium chloride traps [107]. However, these methods can also affect VOC levels and completely removing water vapour has thus far not proved possible. Adsorbent materials $\left(\right.$ e.g. Tenax ${ }^{\oplus}$ ), which have a very low water-binding capacity, can reduce the water vapour effect [116]. Another approach is to leave out known water vapour signals from the 
analysis [117], but by doing this one may lose signals generated by biomarkers on the same sensor; therefore, this potential shortcoming needs to be taken into account.

\section{Breathing pattern}

Exhalation flow-dependency has been reported for acetone [118], ethanol [119], isoprene [120, 121] and pentane [120], suggesting that these compounds derive, at least partially, from the airways. In line with this, exhalation flow alterations significantly affect exhaled breath patterns assessed with e-nose, contributing to the variable ability of these devices to discriminate breathprints [117]. Similarly, exhaled VOC profiles as determined by e-noses integrated with spirometry are dependent on expiratory flow [109]. It is as yet unknown if changes in airway calibre affect VOC concentrations, but e-nose breathprints have been shown to be independent of acute changes in airway calibre in asthma [122].

During single-breath sampling, a single expiratory vital capacity manoeuvre is generally used [104, 107]. During this procedure subjects are instructed to exhale immediately after a deep inhalation to total lung capacity because VOCs, including acetone [118, 119], ethane [120], isoprene [120, 121], methanol and dimethyl sulfide [118], may accumulate in the alveoli and airways during prolonged breath hold. Infants may require tidal breathing sampling with minimal respiratory resistance [123, 124], while VOCs can be sampled from the ventilator circuit in patients ventilated in the intensive care unit $[125,126]$.

\section{Subject/patient}

Potential confounding factors in breath analysis include diet $[119,127,128]$, inter-subject variability in drug elimination [129], pharmacological treatment [87, 130], exercise [15, 131-133], smoking [134, 135] and co-morbidities [136]. Common efforts to reduce the impact of these factors on breath analysis include prohibition of exercise, smoking, food and drink intake 2-3 h prior to testing. Whether these factors improve reliability is, however, still to be determined.

\section{Volatile organic compound measurements}

Exhaled breath analysis can roughly be split into two main streams [137]: 1) an analytical molecule identification-based stream; and 2) a sensor technology, pattern recognition-based stream. The analytical mass spectrometry (MS) track, often coupled to a separation technique like gas chromatography (GC), is focused on identifying biomarker compounds related to particular disease conditions and the accompanying pathophysiology. The second is a cross-reactive sensor technology that is purely based on pattern recognition of complex mixtures. This is represented by e-nose technologies [103, 115] that are used for probabilistic predictive values in relation to health and disease.

\section{Identification of volatile organic compounds and their concentrations}

During MS, ions are created from the VOCs present in a gas mixture. On the basis of the mass-to-charge ratio $(\mathrm{m} / \mathrm{z})$ of their product ions, compounds can be detected and identified. Ionisation is achieved using electron or chemical ionisation. GC-MS and two-dimensional GC-MS (GCxGC-MS) mainly use electron ionisation, causing fragmentation of compounds and giving library-searchable spectra, whereas chemical ionisation and atmospheric pressure chemical ionisation are often used to elucidate structure. Other analytical identification techniques include proton transfer reaction MS (PTR-MS) and selective ion flow tube MS (SIFT-MS), which are driven by soft chemical ionisation. GC-MS is seen as the leading technology for VOC analysis, with very high sensitivity and selectivity. However, it cannot be used for real-time exhaled breath measurements. PTR-MS and SIFT-MS can both be applied in real time and have the option (and limitation) to ionise compounds selectively [138].

The use of MS technology is valuable for gaining insights into pathophysiological pathways in the field of pulmonology. Compounds that can be linked to the presence of pathogenic fungi and bacteria can be found [139-142], along with data on VOCs related to inflammation, obstructive lung diseases and lung cancer $[86,119,143-148]$.

\section{Pattern recognition of volatile organic compounds}

Whenever biomarkers are not known, many non-selective sensors are needed to obtain a fingerprint of the measured VOC mixture $[149,150]$. The registered fingerprints are treated with pattern-recognition techniques (within the machine-learning field) to be recognised as pertinent to certain classes (diseases). This probabilistic classification workflow allows diagnosis, phenotyping and monitoring based on VOC fingerprints:

1) Starting points:

- sensors technology for VOC mixture content capturing and assessment [151-153]

- clinical parameters to be correlated with sensor outputs [154]

- suitable and reproducible exhaled breath sampling protocols [114, 155]. 
2) Explorative analysis:

○ to study sensor correlation with specific (target) parameters

- sensor selection for the target disease.

3) Supervised analysis devoted to:

- disease discrimination (diagnosis and monitoring) $[99,150,156]$

- disease stage identification (diagnosis and monitoring) $[157,158]$

o disease characterisation (phenotyping) $[143,159]$.

Organic and inorganic films and polymers are used as sensing materials and they are coupled with many different working principles: conductometric, acoustic, optical and electrochemical [115]. Each of them needs specific temperature and humidity operating conditions [150, 160]. Sensing material, working principle and operating conditions strongly influence the selection of specific VOC spectra [160]

\section{Calibration}

The quantitative analysis of breath samples by GC-MS [161, 162], e-nose [151, 163], ion mobility spectrometry (IMS) $[164,165]$, field asymmetric IMS [165, 166], SIFT-MS $[167,168]$ etc. requires quality control by means of an appropriate calibration procedure [169-171]. Further details on the required calibration procedures are given in supplement 2 .

\section{Analysis}

Processing

The signal that results from the VOC measurement (ion count in GC-MS or cross-reactive sensor response) has to be processed into a matrix of features that is suitable for statistical analyses [89]. One important preprocessing step is normalisation, which aims to reduce the effect of systematic variation (e.g. due to variability in sample volumes) between samples by adjusting signal intensity by, e.g. 1) total intensity; 2) highest value; or 3) intensity of a standard [171]. However, it remains unclear if the basic assumptions to allow normalisation are always met in breath analysis [89]. Nevertheless, careful preprocessing, normalisation and environmental correction are required for optimal results [109] and therefore should be extensively reported in all studies.

\section{Statistical analysis}

Appropriate statistical analysis is of major importance [89, 95, 136, 172-175], see supplement 3 for further details.

\section{Clinical accuracy}

The potential clinical usage of exhaled breath biomarkers has traditionally been explored by examining associations of the presence of a disease with one or more individual VOCs or particular composite patterns of VOCs $[148,149]$. For correct interpretation of findings (similar to assessing other potential biomarkers), authors should follow international standards to accurately report findings described by different expert panels (e.g. STARD, CONSORT and TRIPOD) [176-179].

Internal validation and external validation

Internal and external validation of omics data is crucial [94-96, 103, 148, 149, 180-187], see supplement 4 for further details.

\section{Priorities for technical research on exhaled volatile organic compounds}

There is a great need for a wide-scale multicentre study to compare different sampling methods, equipment and determination of exhaled volatiles by different techniques at different sites to address issues of standardisation and to assess the current clinical utility of the available technology. Further research is needed both in the technical areas of breath sampling and testing and on the clinical relevance of breathomics [109, 175, 188]. A detailed list of important areas for further research is provided in supplement 5.

Recommendations for future research: There is a great need for further standardisation of sampling and analysis procedures of exhaled breath VOCs to substantiate the promise of volatiles in clinical medicine [103, 137, 189]. Such standardisation requires a sensible balance between imposing restrictions and allowing ample room for innovation [103, 190]. Further details of research priorities are provided in supplement 5. We are still relatively at the beginning of VOC research in medicine and have yet to further discover and define VOCs and VOC patterns with established clinical add-on value with regard to diagnosis, phenotyping or prediction of clinical course in medical practice [191-207]. This will require 
stringent procedures for stepwise validation of composite biomarkers [94-96, 176, 178]. Only then will VOCs find their way into daily clinical management.

In this rapidly growing scientific area we are in the exploratory phase of relevant research. Improved understanding of the source, the dynamics of VOCs present in the breath in health and disease, their influencing factors, and the complex interplay between different compartments and between the microbiome and metabolism [208-213], together with critical evaluation of currently used methods and active development of data handling, analysis and interpretation have changed the landscape in this field at an unexpectedly fast speed [103, 214-217]. Shortening the innovation cycle brings new technology to medical research in the area of VOCs $[217,218]$. The process is further facilitated by studies in other species that help in our understanding of the factors in physiological variability [219-221], which are also aided by active research in the field of infective agents [222, 223].

\section{Exhaled nitric oxide}

The last ATS/ERS recommendations for exhaled NO (FENO) measurements described several aspects of standardisation [2] and are used worldwide. The ATS/ERS 2005 document is still valid and is mostly still applicable in 2016; therefore, these parts are briefly summarised. Since the development of these recommendations, the field has grown further, and new devices have been developed and used. Furthermore, mathematical modelling of pulmonary NO dynamics, sometimes called extended NO analysis, has been developed [224]. The aim of the current document is to add to the existing recommendations by clarifying the terminology further (see Box 1), by evaluating nasal NO measurement in light of recent publications and to introduce recommendations for NO dynamic models in order to compare and pool data for further analysis.

FENO emerged in the 1990s as a noninvasive marker of airway inflammation in asthma, but since then has been studied in many other disease entities, including COPD, scleroderma, obstructive sleep apnoea syndrome, nasal epithelia disorders, cystic fibrosis and hepatopulmonary syndrome [2]. FENO has also been widely used in studies of respiratory effects of environmental exposures [225-227].

\section{Measurement of FENO}

Recommendations for the determination of FENO have been published [2, 228, 229] and the ATS/ERS guidelines [2] that cover most areas are still valid, but there are technical issues that need updating. This was felt to be important even if, regarding clinical utility, the discriminating power (specificity and sensitivity) in diagnosing or tailoring the treatment of asthma has not allowed this method to be part of the World Health Organization (WHO) recommendation for asthma diagnosis or monitoring [230]. $\mathrm{EENO}_{50}$ may be elevated in healthy subjects [231] and may be normal in subjects with asthma [232, 233]. Thus the cause and even the origin of exhaled NO seem to be complex. However, more studies have recently indicated the usefulness of FENO as a biomarker for asthma phenotyping and management [234]. Most specifically, it is now considered that elevated $F \mathrm{ENO}_{50}$ values per se are not sufficient to ascertain the diagnosis of asthma. Rather, high $F \mathrm{ENO}_{50}$ values help to identify T-helper 2 cell-type inflammation, a trait commonly seen in patients with asthma [235]. $\mathrm{FENO}_{50}$ in asthmatic patients is associated with the risk of exacerbations and the likelihood of a positive response to inhaled corticosteroids [236, 237]; therefore, its measurement bears clinical significance. For $\mathrm{FENO}_{50}$ measurement, inhalation to total lung capacity is recommended by the ATS/ERS guideline [2]. However, arguments supporting a more comfortable procedure for the patients without affecting the results

\section{Box 1 Terminology}

FENO fractional concentration of exhaled NO in the gas phase (ppb). Exhalation flow rate is given as a subscript in $\mathrm{mL} \cdot \mathrm{s}^{-1}$. A flow rate of $50 \mathrm{~mL} \cdot \mathrm{s}^{-1}$ is written $F \mathrm{ENO}_{50}$.

FnNO fractional concentration of nasally aspirated/exhaled NO. The flow rate of the aspirated NO, usually $5 \mathrm{~mL} \cdot \mathrm{s}^{-1}$, is given as a subscript in $\mathrm{mL} \cdot \mathrm{s}^{-1}\left(\right.$ e.g. $\left.\mathrm{FnNO}_{5}\right)$. A nasally exhaled NO value at $50 \mathrm{~mL} \cdot \mathrm{s}^{-1}$ is given as $\mathrm{FnNO}_{50}$.

CANO concentration of NO in the gas phase of the alveolar or acinar region ( $\mathrm{ppb}$ ).

CawNO tissue concentration of $\mathrm{NO}$ of the airway wall ( $\mathrm{ppb}$ ).

DawNO airway compartment diffusing capacity of NO from the airway wall to the gas stream $\left(\mathrm{mL} \cdot \mathrm{s}^{-1}\right)$.

JawNO total flux of NO in the conducting airway compartment $\left(\mathrm{nL} \cdot \mathrm{s}^{-1}\right)$ that takes into account the value of $C$ ANO $(J$ awNO $=(C$ awNO$-C A N O) \times D$ awNO $)$. If CANO is zero, the flux is equal to the theoretical total maximum flux, which is $J^{\prime}$ awNO $=C$ awNO $\times D$ awNO.

$\dot{V}_{\text {NO }} \quad$ elimination rate of $\mathrm{NO}\left(\mathrm{pL} \cdot \mathrm{s}^{-1}\right.$ or $\left.\mathrm{nL} \cdot \mathrm{s}^{-1}\right)$.

$\dot{V}_{\mathrm{E}} \quad$ exhalation flow rate $\left(\mathrm{mL} \cdot \mathrm{s}^{-1}\right)$. 
[238] have been put forward [239]. Such methods have been adopted both by clinicians and by manufacturers. In this method, FENO measurement is performed with a deep inhalation through the mouth and slow exhalation, with feedback of the flow rate for the subject. Velum closure is mandatory and achieved by using a positive pressure of $5-20 \mathrm{cmH}_{2} \mathrm{O}$ against exhalation. An approved measure is one in which the flow rate is within $10 \%$ of the target value, i.e. $45-55 \mathrm{~mL} \cdot \mathrm{s}^{-1}$. When a chemiluminescence detector is used for NO determination, a minimum of two NO measurements is recommended by the ATS/ERS guidelines [2]. The technical requirement for acceptable measurements is that the two plateau values should be within $10 \%$ of each other; if not, then another measurement is necessary [2]. In the last 10 years, great developments have been achieved in various methods of NO analysis [240, 241] and comparisons made between them [242]. When using electrochemical sensors, no plateau is visible, and there are limited data demonstrating that performing one exhalation manoeuvre is appropriate for some electrochemical devices, with good repeatability [243, 244]. The ATS/ERS guidelines recommend two measurements and this is still a valid recommendation, although it is appreciated that if only one measurement can be performed owing to financial or other constraints, use of the mentioned handheld devices could provide valuable data.

The above information together with data showing that handheld devices are not interchangeable needs to be considered when these devices are used either for research purposes or for clinical practice. The reasons that these different handheld devices are not interchangeable are likely that some cells have better accuracy than others and the programme applied within the devices limits repeatability. A hypothetical reason is the interval when sampling into the cell takes place. At least $30 \mathrm{~s}$ relaxed tidal breathing is required between measurements. When collecting off-line exhaled breath, it is necessary to be able to separate dead-space gas to be able to compare with on-line NO values. Therefore, the initial 150-200 mL should be discarded, or sampling should be started when a $\mathrm{CO}_{2}$ signal is present, which can help identify the dead-space volume. Ambient NO levels should be recorded and the use of NO-free air for inhalation is preferable.

\section{Considerations}

Various factors that are not disease-related can influence NO values. One such factor is spirometry, which should therefore not be performed prior to NO measurement [2]. Bronchoconstriction may cause a decrease in $\mathrm{FENO}_{50}$ and bronchodilation an increase $[245,246] . \mathrm{ENO}_{50}$ can vary in uncontrolled asthma and is proposed to be a biomarker of asthma control and a predictor of exacerbation [247]. Drugs that may affect airway calibre should be documented as well as anti-inflammatory drugs. A questionnaire for NO measurement is recommended (supplement 6). Mouthwash is recommended when physiological research is done, because bacteria in the mouth can influence exhaled NO concentration. Because this influence is minor and does not have clinical relevance, mouthwash is not required when the measurement is done in clinical practice $[248,249]$. A too-deep inhalation, with over-distension, may affect the patient's control over exhalation flow rate. There is no specific lower age limit for $\mathrm{FENO}_{50}$ measurements and normal values are published for children from 4 years of age. The 2005 ATS/ERS recommendations are still valid for preschool children who are unable to perform appropriate controlled exhalation and for infants [2]. Note that FENO has been shown to be age-dependent in three distinct phases in healthy individuals [250].

\section{Reference values}

Reference values for healthy adult subjects have been published [251-253] and recommended cut-off values have been discussed to help clinical decision-making $[254,255]$. In clinical practice a $F \mathrm{ENO}_{50}$ between $25-50 \mathrm{ppb}$ in adults (20-35 ppb in children) should be judged within the clinical context and NO values $>50 \mathrm{ppb}$ ( $>35 \mathrm{ppb}$ in children) may be used to predict a response to anti-inflammatory therapy $[254,255]$. A personal best $\mathrm{FENO}_{50}$ might be estimated from the use of NO parameters and be most useful when evaluating treatment with anti-inflammatory drugs [256, 257].

\section{Measurement of FnNo}

Within the nasal region, NO output is high from the paranasal sinus epithelium, where inducible nitric oxide synthase is expressed under basal conditions [258]. Altered nasal NO levels have been described in a number of conditions, including allergic rhinitis, sinusitis, nasal polyps, cystic fibrosis and primary ciliary dyskinesia (PCD); a disease characterised by low nasal NO output [259]. Several studies demonstrate that FnNO accurately identifies individuals with PCD, supporting its usefulness as a screening tool [260].

Like FENO, FnNO is flow dependent [239]. Usually the intrinsic flow of the NO analyser could preferably be used, i.e. $5 \mathrm{~mL} \cdot \mathrm{s}^{-1}$. However, the flow rate must be tested. Data can be presented as concentrations but NO output should also be given. The choice of flow rate depends on the subject and methods. There are two recommended methods: aspiration with serial sampling and exhalation with parallel sampling [261263]. Before measurements start the patient should blow their nose and assure free airflow in both nostrils. 
Aspiration with serial sampling

Aspiration is done through one nostril with the use of a tightly fitting nasal olive with the other nostril open. The subject performs a deep inhalation and holds their breath to obtain velum closure, while air circulates from one naris to the other around the posterior nasal septum. Velum closure may also be obtained by oral expiration against a resistance of $10 \mathrm{cmH}_{2} \mathrm{O}$, by pursed-lip breathing via the mouth, or by voluntary elevation of the soft palate. Velum closure can be monitored by measuring nasal $\mathrm{CO}_{2}$. In infants and children who cannot hold their breath, measurement can be obtained during silent tidal breathing although values tend to vary more with this method.

\section{Exhalation with parallel sampling}

Measurement is done after a deep inhalation with NO-free gas, followed by slow exhalation through the nose (with the mouth closed) into a tightly fitted mask covering the nose [262] or via parallel tightly fitting nasal olives [263]. The subject should have feedback of the flow rate. An approved measurement is one in which the flow rate is between $45-55 \mathrm{~mL} \cdot \mathrm{s}^{-1}$ and a plateau is established at $10 \mathrm{~s}$. If NO values vary more than $10 \%$ [264], another measurement should be added and a mean value displayed. Additional information to record is the ratio between $\mathrm{FENO}_{50}$ and $\mathrm{FnNO}_{50}$.

Measurements of nasal NO during humming can be done to specifically study if there is gas transfer between paranasal sinuses and the nasal cavity [265].

Recommendations for future research: On-line FnNO measurement has been well developed but the optimal measurement technique is yet to be determined. Determination of the optimal sound frequency for humming needs further research. The available studies are flawed by a small numbers of subjects and the use of multiple methods, such as different NO analysers, sampling flow and breath manoeuvres. Low flow rates require longer to reach an NO plateau than higher flow rates and can give values outside the calibration range for the instrument. Most studies in the literature employ a chemiluminescence method, sampling nasal gas by aspiration directly from one nostril, using the intrinsic flow of the chemiluminescence analyser or an external pump. The recent introduction of portable electrochemical devices for handheld NO measurements poses additional methodological difficulties, but the use of exhalation at a flow rate of $50 \mathrm{~mL} \cdot \mathrm{s}^{-1}$ can be recommended.

A reliable and standardised method for FnNO measurement is necessary to enable comparison of results from different laboratories and to formulate appropriate reference values.

Researchers have promoted nasal NO measurements as being potentially useful in screening for disease and in monitoring the effects of treatment. However, this has been proved only for PCD and more work is needed to establish nasal $\mathrm{NO}$ as a potential biomarker of other diseases.

\section{Reference values}

Reference values, although desirable, are not available. Cut-off values have been proposed based on a limited number of healthy controls and diseased patients but at different flow rates [266-269].

\section{Estimation of alveolar and airway nitric oxide parameters}

Exhaled NO at low flow rates reflects NO dynamics mainly in the large central airways and is quite insensitive to the changes in NO dynamics in the periphery of the lungs (small airways and lung parenchyma). Mathematical modelling of pulmonary NO dynamics, sometimes called extended NO analysis, has been presented based on a simple and robust two-compartment model of the lung. In short, the model consists of an expansible part representing NO dynamics in respiratory bronchioles and alveoli (alveolar or acinar compartment) and a single cylindrical tube representing larger conducting airways from the trachea to respiratory bronchioles (bronchial compartment) [270, 271]. The model has been further fine-tuned by taking into account the increasing cross-sectional area of airways towards the lung periphery (trumpet-shaped airways) and the possibility of axial back diffusion of NO from conducting airways towards the alveoli [272]. Statistical methods have also been used to improve the estimation of NO dynamics [273].

\section{General equation of the two-compartment model}

The two-compartment model predicts FENO (or NO output) as a function of flow through the non-linear equation:

$$
\dot{V}_{\mathrm{NO}}=\dot{V}_{\mathrm{E}} \times F_{\mathrm{ENO}}=\dot{V}_{\mathrm{E}} \times\left(C_{\mathrm{awNO}}+\left(C_{\mathrm{ANO}}-C_{\mathrm{awNO}}\right) \times \exp \left(-D_{\mathrm{awNO}} / \dot{V}_{\mathrm{E}}\right)\right)
$$


JawNO can be calculated as follows:

$$
J_{\mathrm{awNO}}=\left(C_{\mathrm{awNO}}-C_{\mathrm{ANO}}\right) \times D_{\mathrm{awNO}}
$$

The most frequently used models in the literature are the linear and the non-linear models. When new models are developed they should preferably be compared to one of these.

Non-linear model: Fitting a non-linear curve (Eq. 1) on a plot of NO output versus flow rate allows the derivation of CANO, DawNO and CawNo [271]. The Högman \& Merilänen Algorithm (HMA) is such a model $[239,274,275]$. A special added feature of the approach by the HMA is to use an algorithm to test if the measured set of data points is mathematically consistent with the model. The condition required for data to guarantee a valid solution for DawNO and CawNO can be written in general form:

$$
\frac{F_{\mathrm{ENO}_{\text {low }}}-F_{\mathrm{ENO}_{\text {medium }}}}{F_{\mathrm{ENO}_{\text {medium }}}-F_{\mathrm{ENO}_{\text {high }}}}<\frac{\dot{V}_{\mathrm{E} \cdot \text { high }}}{\dot{V}_{E \cdot \text { low }}} \times \frac{\dot{V}_{\text {E·medium }}-\dot{V}_{\mathrm{E} \cdot \text { low }}}{\dot{V}_{\mathrm{E} \cdot \text { high }}-\dot{V}_{\mathrm{E} \cdot \text { medium }}}
$$

If this is not the case, the data set suffers from errors in measuring the flow rate or the NO concentration, or both. Then the measured data points are not mathematically consistent with the model.

The results of the NO parameters (CANO, CawNO and DawNO) can be fed into an algorithm in a standard Microsoft Excel environment to create a curve form with its respective flow rates and NO exhaled volumes. The $\mathrm{FENO}_{50}$ is estimated and given for comparison to the measured $\mathrm{FENO}_{50}$ as a quality control. Non-linear modelling has the least error, suggesting it is the best method at the moment [276], although it is more challenging for the patient.

Linear model: A Taylor's development of Eq. 1 around zero limited to the first term allows a simpler model to be proposed that linearly links NO output to flow rate [270]:

$$
\dot{V}_{\mathrm{NO}}=C_{\mathrm{ANO}} \times \dot{V}_{\mathrm{E}}+J_{\mathrm{awNO}}
$$

A linear regression of NO output against flow rate gives CANO as the slope of the line and JawNO as the intercept on the y-axis. The $r$-value of the regression line is mandatory because this gives the quality of the measurements, and should be $>0.95$.

\section{Flows}

The same technique as for $\mathrm{FENO}_{50}$ should be applied, but the flow used must be chosen based on which method of extended NO analysis chosen, namely the linear or non-linear method. The exhaled NO plateau value is normally achieved after $10 \mathrm{~s}$ at a flow of $50 \mathrm{~mL} \cdot \mathrm{s}^{-1}$. The 2005 ATS/ERS document recommended the plateau NO concentration be evaluated over a $3 \mathrm{~s}$ window [2], which has been included in the software of many analysers. With extended NO measurement, it takes longer to reach the plateau value at a low exhalation flow rate than at high flow rates. The plateau value at high flow rates may not extend for $3 \mathrm{~s}$ and may therefore be manually judged.

Non-linear model: NO values from at least three flows are needed: one low $\left(\leqslant 20 \mathrm{~mL} \cdot \mathrm{s}^{-1}\right)$, one medium $\left(100 \mathrm{~mL} \cdot \mathrm{s}^{-1}\right)$ and one high $\left(350 \mathrm{~mL} \cdot \mathrm{s}^{-1}\right.$ or even $\left.400 \mathrm{~mL} \cdot \mathrm{s}^{-1}\right)$ [270]. A minimum of two measurements are done on each flow and mean values of flows and NO concentrations are used to calculate the NO parameters. $\mathrm{FENO}_{50}$ can be estimated. For children and adults with expiratory difficulties who are unable to perform the high flow rate, a lower flow rate can be accepted if the estimated $\mathrm{FENO}_{50}$ is found to be within $5 \mathrm{ppb}$ of the measured $\mathrm{FENO}_{50}$. This is only applicable if the measured set of data points is mathematically consistent.

Linear model: In practice, the linear model starts with a measurement of $\mathrm{FENO}_{50}$ that should always be given for comparison but is not included in the model. Then three exhalation flows of at least $100 \mathrm{~mL} \cdot \mathrm{s}^{-1}$ or higher with increasing steps are performed, with the highest flow rate of $350 \mathrm{~mL} \cdot \mathrm{s}^{-1}$, or even $400 \mathrm{~mL} \cdot \mathrm{s}^{-1}$. A minimum of two measurements are done for each flow rate. When children are unable to perform the highest flow rate, a lower one can be accepted, i.e. $250 \mathrm{~mL} \cdot \mathrm{s}^{-1}$. NO output is calculated for each measurement by using the measured flows with the corresponding NO values. NO eliminations are plotted against exact measured flows and a regression line is drawn.

\section{Recommendations for future research}

The most important advantage of modelling NO dynamics is the gain of CANO that may be useful in assessing inflammation in small airways or lung parenchyma both in airway diseases and interstitial lung 
diseases [224]. JawNO is closely related to $\mathrm{FENO}_{50}$ and does not necessarily add much clinical value over $F_{E_{N}{ }_{50}}$, but dividing JawNO into its components, namely CawNO and DawNO, can increase understanding of the physiological processes with increased NO excretion from conducting airways.

The drawback of modelling NO dynamics is the need for a more complex estimation method. Mathematically, at least two NO values at different flow rates $\left(\geqslant 100 \mathrm{~mL} \cdot \mathrm{s}^{-1}\right)$ must be used to compute CANO and JawNO, reflecting NO dynamics in the peripheral compartment and central compartment, respectively [270, 277]. To divide JawNO into its components CawNO and DawNO, a third low $\left(<20 \mathrm{~mL} \cdot \mathrm{s}^{-1}\right)$ flow must be included [275]. In addition, a number of different mathematical solutions to calculate these NO parameters have been presented [271] and standardisation of both flows and mathematics is therefore needed to allow for comparison between studies.

Models of NO production and transport incorporating molecular diffusion emphasised that the latter brings back NO molecules from peripheral airways into the alveolar compartment, increasing CANO independently from in situ NO production [272, 278]: the so-called back-diffusion phenomenon. Therefore, CANO correction formulae have been proposed based on airway NO output. It is extremely important to understand that these corrections were established, and are therefore only applicable, in healthy subjects or in patients free of obstruction. In case of peripheral reduction of airway calibre, back diffusion may be less important and blind application of these formulae in disease states may lead to overcorrection [275, 279]. Calculations of NO parameters are also flow dependent and the use of correction factors will over-adjust the CANO, sometimes into negative values [275]. Therefore, the use of correction factors for axial back diffusion is not recommended (supplement 7).

If, despite no error detection in the data set, quality controls ( $r>0.95$ for the linear model or Eq. 3 for the non-linear model) are not fulfilled or a negative CANO value is derived, the models may be inadequate. Physiologically, a calculated CANO should be positive. A negative CANO is more an indication that the model of NO production of the respiratory system is inadequate.

\section{Reference values}

There are only two publications that provide reference values for healthy adults [252] and children [280]. A few publications report values in children with asthma using the linear model [279-283] and the non-linear model [284-286], but further research is needed to evaluate their applicability in clinical settings.

\section{Instrumental considerations for nitric oxide measurements}

Basic equipment specifications for NO analysers have previously been described [2]. Currently there are several technologies available for clinical use that are based on chemiluminescence, electrochemical sensing and laser-based detection [240]. The chemiluminescence devices were the first to be implemented and are therefore considered as the standard technique. All later-developed detection methods for measuring NO are introduced in comparison to chemiluminescence.

\section{Chemiluminescence instruments}

This type of analyser measures NO indirectly, via light generation due to a chemical reaction with ozone. Calibration is generally recommended once a month with a calibration gas up to $2000 \mathrm{ppb}$ and zero is set daily. In addition, a yearly check of chemical reaction converters and the ozone generator and its peripheral components is required. Chemiluminescence instruments provide a fast response time, between 0.5 and $0.7 \mathrm{~s}$, and a good detection limit $(0.1-0.5 \mathrm{ppb})$. Repeated measurements can be performed directly. The analysers can be equipped with a unit for controlling the exhalation flow rate. The investment and running costs are high for these instruments, limiting their use in routine clinical applications or home monitoring.

\section{Electrochemical sensors}

Electrochemical sensors have quickly gained popularity because they are handheld devices, weighing $<1 \mathrm{~kg}$. They measure NO concentration via a detectable electrical signal (e.g. current). Their detection range is from about $5 \mathrm{ppb}$ up to $300 \mathrm{ppb}$ and has an accuracy of $\pm 5 \mathrm{ppb}$ or $\pm 10 \%$ of the measured value. The response time is $<10 \mathrm{~s}$ and the analysing time is $60-100 \mathrm{~s}$. In contrast to chemiluminescence analysers, the electrochemical technology that supports the handheld analysers does not allow for pre-test calibration. Each analyser includes a replaceable sensor that is changed after $\sim 1-2$ years or after a number of valid measurements that is specified by the manufacturer. Because no regular calibration can be performed, the performance characteristics of such analysers might change over time or when a sensor is replaced [287]. The analysers are equipped with a pressure measurement set to perform an exhalation pressure of $10-20 \mathrm{cmH}_{2} \mathrm{O}$ and maintain a fixed flow rate of $50 \pm 5 \mathrm{~mL} \cdot \mathrm{s}^{-1}$. The patient is either guided by the display or by a flow indicator.

Electrochemical analysers are exclusively used for $\mathrm{FENO}_{50}$ measurements [243, 288]. The reproducibility of the measurements is less than $3 \mathrm{ppb}$ of the measured value for values $<30 \mathrm{ppb}$ and $<10 \%$ of the measured 
value for values $>30 \mathrm{ppb}$ [288]. The difference in $\mathrm{FENO}_{50}$ values when comparing with the standard chemiluminescence technique is within $\pm 4-10 \mathrm{ppb}$. These results are considered by most users to be clinically acceptable [243]. Some analysers consider one exhalation sufficient for reliable clinical data; for others, at least three exhalations are necessary [241]. For children, multiple tests may be necessary because the analysers do not record $\mathrm{FENO}_{50}$ from poor exhalation manoeuvres, a frequent situation when measuring exhaled NO in children. In general, electrochemical sensors appear to be suitable for routine clinical practice.

\section{Additional techniques}

Other small sensors are under development, such as the smart breath health diagnostic system [289] based on smart solid-state microsensor technology. Optical sensors are also available for the detection of NO concentrations at low levels ( $\mathrm{ppb}$ ). These measure the decrease of light intensity from a laser source due to absorption by NO. Several research groups have developed laser-based NO sensors [286, 290-294]. The instrument is designed for multicomponent analysis using lasers $\left(\mathrm{NO}, \mathrm{CO}_{2}\right.$ with one quantum cascade laser and $\mathrm{CO}$ and $\mathrm{N}_{2} \mathrm{O}$ with another), can detect $<0.3 \mathrm{ppb}$ of $\mathrm{NO}$ within $1 \mathrm{~s}$, and includes a breath sampling system for multiple exhalation flows.

\section{Technical maintenance}

Chemiluminescence instruments need daily maintenance of flow rate and NO zero setting due to drift of the signals. Calibrations of $\mathrm{NO}$ and flow rate are done at intervals recommended by the manufacturer but any drift of the signal should be corrected before measurements are taken. Electrochemical sensors need zero setting and manufacturers present different solutions. Laser-based analysers do not require consumables, allowing for minimal maintenance. An indication of flow rate should be mandatory given that the NO signal is flow dependent. There are different methods to measure exhalation flow rate and it is critical that NO measurement is performed at the exact flow rate that it is aimed at. Compared to electrochemical cells, chemiluminescence instruments have the advantage of a fast response time and the ability to measure $\mathrm{NO}$ at a wide range of flow rates. The use of $\mathrm{CO}_{2}$ is recommended with off-line measurements or with nasal NO measurements to indicate that accurate sampling is performed.

\section{Conclusion for exhaled nitric oxide}

The current statement does not aim to interpret the potential clinical uses of FENO measurement or extended NO analyses. Despite the large number of studies that exist in the field of exhaled nitric oxide measurement, further studies are needed with regards the reference values of NO modelling to reach data comparability. Further exploratory work is also needed for the appropriate standardisation of nasal NO measurement.

\section{Particles in exhaled breath}

Exhaled breath contains an aerosol of small particles. All non-volatiles identified in EBC are probably derived from these particles. Condensation is, however, an inefficient method to collect non-volatiles because many particles pass the condenser without being collected. Importantly, there is large inter-individual variation in the endogenous production of exhaled particles that needs to be accounted for when aiming at quantitative analyses [295, 296].

The number of particles in exhaled breath (PEx) is very low during tidal breathing, much lower than in the ambient air, and does not seem to be influenced by obstructive airway disease [297]. By using a breathing manoeuvre allowing for airway opening following airway closure, there is a substantial increase (up to 18-fold) of the number of PEx [298], enhancing analyses of their chemical composition but also indicating the origin of these particles. A decrease in the number of PEx in subjects with airway obstruction has been observed [299]. These results indicate the majority of PEx originate from the very distal airways where airway closure and reopening take place. This conclusion is further supported by a dose-dependent increase in the number of PEx with increasing breath-holding times at residual lung volume and the decreasing number of PEx if breath holding is performed at total lung volume [300], the latter possibly causing a deposition of the largest formed particles within the airways.

PEx, when sampled in a manner that allows for airway opening, contain $~ 75 \%$ phospholipids and $25 \%$ proteins. The observed phospholipid composition of PEx is similar to that of the respiratory tract lining fluid. Time-of-flight secondary ion MS has shown that the phospholipid composition of PEx is altered in asthma and that subjects with asthma have fewer unsaturated phospholipids and that smokers have more protonated phospholipids than non-smokers [301]. In animal studies, the altered phospholipid composition of surfactant has recently been strongly associated with the development of e.g. COPD [302], indicating that this is an interesting area for future research. 
In a shotgun proteomic study of pooled PEx samples from healthy individuals [301, 303], 124 proteins were identified, the majority of which were extracellular. Amylase was not detected, excluding the possibility of oral contamination of the PEx samples, and neither were any mucins, further supporting the peripheral origin of the samples.

An ELISA has been adapted and validated to analyse surfactant protein-A (SP-A) in PEx [304]. When examining the levels of SP-A in PEx and in EBC after sampling of $100 \mathrm{~L}$ of exhaled breath from nine healthy subjects, SP-A was well above the detection limit in all PEx samples, but only in five out of 18 EBC samples. SP-A in PEx has also been shown to be increased in COPD (stage II-IV) compared to in age-matched healthy controls, and correlated significantly with lung function in patients with COPD [305]. A new method to sample non-volatiles in exhaled breath, based on impaction, has been developed: Particles in Exhaled Air ( $\left.\mathrm{PExA}^{\mathrm{TM}}\right)$. This method enables the number of exhaled particles in different size intervals to be counted, and thereby permits quantitative chemical analyses [284, 289]. It also allows repeated sampling of the respiratory tract lining fluid from the small airways. Other methods to sample exhaled particles, based on collection by filters, by liquid impingement and by using wetted wall cyclones, have so far only been evaluated in experimental settings [295, 300]; Teflon filters performed best, catching on average 20$30 \%$ of cytokines from a nebulised aerosol with spiked concentrations of cytokines [306]. The relatively low efficiency of particle collection by this method might explain why the concentration of these cytokines is below the detection limit of ELISA tests (while in EBC at least some of them are detectable). Using the PExA method, another approach has therefore been necessary, i.e. to determine the more common constituents of the lining fluid of small airways both in the healthy and disease states. This work is, however, in its early infancy.

In conclusion, sampling of exhaled particles provides a novel opportunity to identify, quantify and monitor pathological processes in the small airways. There have as of yet been no multicentre comparative studies, but standardisation of this method is crucial for future research, including the breathing manoeuvre, sampling technique and analysis of the samples.

Recommendations for future research: Further research is suggested to facilitate understanding of particle release from the airways and to better understand the potential clinical relevance of particles as exhaled biomarkers.

\section{Overall conclusions and future expectations}

Exhaled biomarkers form a rapidly growing field of research [307]. Previous guidelines have contributed to the fruitful networking and streamlining of research efforts in the field. The expectation of this document is the same: to provide an overview of the current knowledge and to look for new horizons. As in many other areas of medical research, the roots of exhaled biomarker research go back centuries to when olfaction (smell of the breath of the patient) was mentioned as being important in the detection of liver and renal failure. This, together with the ability of canines to discriminate between breath samples obtained from patients with different cancers and from healthy subjects [308], highlights those specific aspects that link the field of exhaled biomarkers to the ancient communication channels through volatile compounds. Honeybees can be trained to signal the presence of heroin and research into insect-based biosensors may also have an effect on the field of exhaled biomarkers [309, 310]. As the field of exhaled biomarkers continues to grow, we may rely more on further development of artificial or even biosensor-derived olfaction systems to provide an even firmer background for the recognition of biomarker patterns in the breath. Breathomics may become a cornerstone of personalised medicine [311], but this will require more attention to be paid to the human microbiome and its confounding effect on "our" breath biomarker profile [312]. The potential offered by the rapidly growing area of e-nose technology resulting in wearable e-noses (fabric-based electronic sensors) are also great for "smelling" the difference between health and disease [313]. Eventually, medically acceptable, positive and/or negative predictive values for diagnoses, phenotypes and prediction of clinical course have to be delivered, before widespread implementation can be established.

\section{References}

1 Horvath I, Hunt J, Barnes PJ, et al. Exhaled breath condensate: methodological recommendations and unresolved questions. Eur Respir J 2005; 26: 523-548.

2 ATS/ERS recommendations for standardized procedures for the online and offline measurement of exhaled lower respiratory nitric oxide and nasal nitric oxide, 2005. Am J Respir Crit Care Med 2005; 171: 912-930.

3 Rosias PP, Robroeks CM, Niemarkt HJ, et al. Breath condenser coatings affect measurement of biomarkers in exhaled breath condensate. Eur Respir J 2006; 28: 1036-1041.

4 Czebe K, Barta I, Antus B, et al. Influence of condensing equipment and temperature on exhaled breath condensate $\mathrm{pH}$, total protein and leukotriene concentrations. Respir Med 2008; 102: 720-725.

5 Rosias PP, Robroeks CM, Kester A, et al. Biomarker reproducibility in exhaled breath condensate collected with different condensers. Eur Respir J 2008; 31: 934-942. 
Huttmann EM, Greulich T, Hattesohl A, et al. Comparison of two devices and two breathing patterns for exhaled breath condensate sampling. PLoS One 2011; 6: e27467.

Loyola BR, Bhushan A, Schivo M, et al. Temperature changes in exhaled breath condensate collection devices affect observed acetone concentrations. J Breath Res 2008; 2: 037005.

Vyas A, Zhang Q, Gunaratne S, et al. The effect of temperature on exhaled breath condensate collection. J Breath Res 2012; 6: 036002.

Rosias P. Methodological aspects of exhaled breath condensate collection and analysis. J Breath Res 2012; 6: 027102. Corradi M, Goldoni M, Caglieri A, et al. Collecting exhaled breath condensate (EBC) with two condensers in series: a promising technique for studying the mechanisms of EBC formation, and the volatility of selected biomarkers. J Aerosol Med Pulm Drug Deliv 2008; 21: 35-44.

Hoffmeyer F, Raulf-Heimsoth M, Harth V, et al. Comparative analysis of selected exhaled breath biomarkers obtained with two different temperature-controlled devices. BMC Pulm Med 2009; 9: 48.

Liu J, Thomas PS. Relationship between exhaled breath condensate volume and measurements of lung volumes. Respiration 2007; 74: 142-145.

Reinhold P, Jaeger J, Schroeder C. Evaluation of methodological and biological influences on the collection and composition of exhaled breath condensate. Biomarkers 2006; 11: 118-142.

Chen SF, Danao MG. Decomposition and solubility of $\mathrm{H}_{2} \mathrm{O}_{2}$ : implications in exhaled breath condensate. $J$ Breath Res 2013; 7: 046001.

A, Galffy G, Tamasi L, et al. Exhaled breath condensate $\mathrm{pH}$ decreases during exercise-induced bronchoconstriction. Respirology 2014; 19: 563-569.

Reinhold P, Knobloch H. Exhaled breath condensate: lessons learned from veterinary medicine. J Breath Res 2010; 4: 017001.

Vass G, Huszár E, Barát E, et al. Comparison of nasal and oral inhalation during exhaled breath condensate collection. Am J Respir Crit Care Med 2003; 167: 850-855.

Latzin P, Beck J, Bartenstein A, et al. Comparison of exhaled breath condensate from nasal and oral collection. Eur J Med Res 2003; 8: 505-510.

Zetterquist W, Marteus H, Kalm-Stephens $\mathrm{P}$, et al. Oral bacteria-the missing link to ambiguous findings of exhaled nitrogen oxides in cystic fibrosis. Respir Med 2009; 103: 187-193.

Knobloch $\mathrm{H}$, Becher G, Decker M, et al. Evaluation of $\mathrm{H}_{2} \mathrm{O}_{2}$ and $\mathrm{pH}$ in exhaled breath condensate samples: methodical and physiological aspects. Biomarkers 2008; 13: 319-341.

Hoffmann HJ, Tabaksblat LM, Enghild JJ, et al. Human skin keratins are the major proteins in exhaled breath condensate. Eur Respir J 2008; 31: 380-384.

Miller MR, Crapo R, Hankinson J, et al. General considerations for lung function testing. Eur Respir J 2005; 26 : $153-161$.

Laube BL, Janssens HM, de Jongh FH, et al. What the pulmonary specialist should know about the new inhalation therapies. Eur Respir J 2011; 37: 1308-1331.

Koczulla AR, Noeske S, Herr C, et al. Ambient temperature impacts on $\mathrm{pH}$ of exhaled breath condensate. Respirology 2010; 15: 155-159. asthma. Curr Top Med Chem 2016; 16: 1550-1560.

Kullmann T, Barta I, Lázár Z, et al. Exhaled breath condensate pH standardised for $\mathrm{CO}_{2}$ partial pressure. Eur Respir J 2007; 29: 496-501.

Hoffmeyer F, Berresheim H, Beine A, et al. Methodological implications in $\mathrm{pH}$ standardization of exhaled breath condensate. J Breath Res 2015; 9: 036003.

Effros RM, Casaburi R, Porszasz J, et al. Exhaled breath condensates: analyzing the expiratory plume. Am J Respir Crit Care Med 2012; 185: 803-804.

Grob NM, Aytekin M, Dweik RA. Biomarkers in exhaled breath condensate: a review of collection, processing and analysis. J Breath Res 2008; 2: 037004.

Bloemen K, Hooyberghs J, Desager K, et al. Non-invasive biomarker sampling and analysis of the exhaled breath proteome. Proteomics Clin Appl 2009; 3: 498-504.

Robroeks CM, van de Kant KD, Jobsis Q, et al. Exhaled nitric oxide and biomarkers in exhaled breath condensate indicate the presence, severity and control of childhood asthma. Clin Exp Allergy 2007; 37: 1303-1311.

Janicka M, Kubica P, Kot-Wasik A, et al. Sensitive determination of isoprostanes in exhaled breath condensate samples with use of liquid chromatography-tandem mass spectrometry. J Chromatogr B Analyt Technol Biomed Life Sci 2012; 893-894: 144-149.

Ohanian AS, Zimmerman J, Debley JS. Effects of sample processing, time and storage condition on cysteinyl leukotrienes in exhaled breath condensate. J Breath Res 2010; 4: 046002.

Esther CR Jr, Boysen G, Olsen BM, et al. Mass spectrometric analysis of biomarkers and dilution markers in exhaled breath condensate reveals elevated purines in asthma and cystic fibrosis. Am J Physiol Lung Cell Mol Physiol 2009; 296: L987-L993.

Lazar Z, Cervenak L, Orosz M, et al. Adenosine triphosphate concentration of exhaled breath condensate in asthma. Chest 2010; 138: 536-542.

Effros RM, Casaburi R, Porszasz J, et al. Comment on 'the effect of temperature on exhaled breath condensate collection'. J Breath Res 2012; 6: 048001; author reply 048002.

Marek EM, Volke J, Hawener I, et al. Measurements of lactate in exhaled breath condensate at rest and after maximal exercise in young and healthy subjects. J Breath Res 2010; 4: 017105.

Johnson GR, Morawska L. The mechanism of breath aerosol formation. J Aerosol Med Pulm Drug Deliv 2009; 22: 229-237.

Almstrand AC, Bake B, Ljungstrom E, et al. Effect of airway opening on production of exhaled particles. J Appl Physiol 2010; 108: 584-588.

Schwarz K, Biller H, Windt $\mathrm{H}$, et al. Characterization of exhaled particles from the healthy human lung-a systematic analysis in relation to pulmonary function variables. J Aerosol Med Pulm Drug Deliv 2010; 23: 371-379.

Larsson P, Mirgorodskaya E, Samuelsson L, et al. Surfactant protein A and albumin in particles in exhaled air. Respir Med 2012; 106: 197-204. 
42 Nunez-Naveira L, Marinas-Pardo LA, Amor-Carro O, et al. Determination of ELISA reproducibility to detect protein markers in exhaled breath condensate. J Breath Res 2012; 6: 046003.

43 Bikov A, Galffy G, Tamasi L, et al. Exhaled breath condensate $\mathrm{pH}$ is influenced by respiratory droplet dilution. J Breath Res 2012; 6: 046002.

44 Brooks SM, Haight RR, Gordon RL. Age does not affect airway pH and ammonia as determined by exhaled breath measurements. Lung 2006; 184: 195-200.

45 Kullmann T, Barta I, Antus B, et al. Drinking influences exhaled breath condensate acidity. Lung 2008; 186 : 263-268.

46 Marteus H, Tornberg DC, Weitzberg E, et al. Origin of nitrite and nitrate in nasal and exhaled breath condensate and relation to nitric oxide formation. Thorax 2005; 60: 219-225.

47 van Beurden WJ, Dekhuijzen PN, Harff GA, et al. Variability of exhaled hydrogen peroxide in stable COPD patients and matched healthy controls. Respiration 2002; 69: 211-216.

48 Gajdocsi R, Bikov A, Antus B, et al. Assessment of reproducibility of exhaled hydrogen peroxide concentration and the effect of breathing pattern in healthy subjects. J Aerosol Med Pulm Drug Deliv 2011; 24: 271-275.

49 Walsh BK, Mackey DJ, Pajewski T, et al. Exhaled-breath condensate $\mathrm{pH}$ can be safely and continuously monitored in mechanically ventilated patients. Respir Care 2006; 51: 1125-1131.

50 Colombo C, Faelli N, Tirelli AS, et al. Analysis of inflammatory and immune response biomarkers in sputum and exhaled breath condensate by a multi-parametric biochip array in cystic fibrosis. Int J Immunopathol Pharmacol 2011; 24: 423-432.

51 Tufvesson E, Bozovic G, Hesselstrand R, et al. Increased cysteinyl-leukotrienes and 8-isoprostane in exhaled breath condensate from systemic sclerosis patients. Rheumatology (Oxford) 2010; 49: 2322-2326.

52 Lin JL, Bonnichsen $\mathrm{MH}$, Nogeh EU, et al. Proteomics in detection and monitoring of asthma and smoking-related lung diseases. Expert Rev Proteomics 2010; 7: 361-372.

53 Kurova VS, Anaev EC, Kononikhin AS, et al. Proteomics of exhaled breath: methodological nuances and pitfalls. Clin Chem Lab Med 2009; 47: 706-712.

54 Bentur L, Hellou E, Goldbart A, et al. Laboratory and clinical acute effects of active and passive indoor group water-pipe (narghile) smoking. Chest 2014; 145: 803-809.

55 Nowak D, Kasielski M, Pietras T, et al. Cigarette smoking does not increase hydrogen peroxide levels in expired breath condensate of patients with stable COPD. Monaldi Arch Chest Dis 1998; 53: 268-273.

56 Kasielski M, Nowak D. Long-term administration of N-acetylcysteine decreases hydrogen peroxide exhalation in subjects with chronic obstructive pulmonary disease. Respir Med 2001; 95: 448-456.

57 Baraldi E, Carraro S, Alinovi R, et al. Cysteinyl leukotrienes and 8-isoprostane in exhaled breath condensate of children with asthma exacerbations. Thorax 2003; 58: 505-509.

58 Kostikas K, Papatheodorou G, Psathakis K, et al. Oxidative stress in expired breath condensate of patients with COPD. Chest 2003; 124: 1373-1380.

59 Montuschi P, Kharitonov SA, Ciabattoni G, et al. Exhaled leukotrienes and prostaglandins in COPD. Thorax 2003; 58: 585-588.

60 Koutsokera A, Loukides S, Gourgoulianis KI, et al. Biomarkers in the exhaled breath condensate of healthy adults: mapping the path towards reference values. Curr Med Chem 2008; 15: 620-630.

61 Paget-Brown AO, Ngamtrakulpanit L, Smith A, et al. Normative data for $\mathrm{pH}$ of exhaled breath condensate Chest 2006; 129: 426-430.

62 Hunt JF, Fang K, Malik R, et al. Endogenous airway acidification. Implications for asthma pathophysiology. Am J Respir Crit Care Med 2000; 161: 694-699.

63 Liu L, Teague WG, Erzurum S, et al. Determinants of exhaled breath condensate $\mathrm{pH}$ in a large population with asthma. Chest 2011; 139: 328-336.

64 Kostikas K, Papatheodorou G, Ganas K, et al. $\mathrm{pH}$ in expired breath condensate of patients with inflammatory airway diseases. Am J Respir Crit Care Med 2002; 165: 1364-1370.

65 Papaioannou AI, Loukides S, Minas M, et al. Exhaled breath condensate $\mathrm{pH}$ as a biomarker of COPD severity in ex-smokers. Respir Res 2011; 12: 67.

66 Antus B, Barta I, Kullmann T, et al. Assessment of exhaled breath condensate $\mathrm{pH}$ in exacerbations of asthma and chronic obstructive pulmonary disease: a longitudinal study. Am J Respir Crit Care Med 2010; 182: 1492-1497.

67 Teng Y, Sun P, Zhang J, et al. Hydrogen peroxide in exhaled breath condensate in patients with asthma: a promising biomarker? Chest 2011; 140: 108-116.

68 Antus B, Harnasi G, Drozdovszky O, et al. Monitoring oxidative stress during chronic obstructive pulmonary disease exacerbations using malondialdehyde. Respirology 2014; 19: 74-79.

69 Nguyen TA, Woo-Park J, Hess M, et al. Assaying all of the nitrogen oxides in breath modifies the interpretation of exhaled nitric oxide. Vascul Pharmacol 2005; 43: 379-384.

70 Carraro S, Giordano G, Piacentini G, et al. Asymmetric dimethylarginine in exhaled breath condensate and serum of children with asthma. Chest 2013; 144: 405-410.

71 Montuschi P, Martello S, Felli M, et al. Liquid chromatography/mass spectrometry analysis of exhaled leukotriene B4 in asthmatic children. Respir Res 2005; 6: 119.

72 Syslova K, Bohmova A, Demirbag E, et al. Immunomagnetic molecular probe with UHPLC-MS/MS: a promising way for reliable bronchial asthma diagnostics based on quantification of cysteinyl leukotrienes. J Pharm Biomed Anal 2013; 81-82: 108-117.

73 Carpenter CT, Price PV, Christman BW. Exhaled breath condensate isoprostanes are elevated in patients with acute lung injury or ARDS. Chest 1998; 114: 1653-1659.

74 Sanak M, Gielicz A, Bochenek G, et al. Targeted eicosanoid lipidomics of exhaled breath condensate provide a distinct pattern in the aspirin-intolerant asthma phenotype. J Allergy Clin Immunol 2011; 127: 1141-1147.

75 Montuschi P, Mondino C, Koch P, et al. Effects of a leukotriene receptor antagonist on exhaled leukotriene E4 and prostanoids in children with asthma. J Allergy Clin Immunol 2006; 118: 347-353.

76 Montuschi P, Macagno F, Parente P, et al. Effects of cyclo-oxygenase inhibition on exhaled eicosanoids in patients with COPD. Thorax 2005; 60: 827-833.

77 Lázár Z, Vass G, Huszár É, et al. Exhaled breath condensate: adenosine, ATP and other purines. Eur Respir Mon 2010; 49: 183-195. 
de Laurentiis G, Paris D, Melck D, et al. Metabonomic analysis of exhaled breath condensate in adults by nuclear magnetic resonance spectroscopy. Eur Respir J 2008; 32: 1175-1183.

Montuschi P, Paris D, Melck D, et al. NMR spectroscopy metabolomic profiling of exhaled breath condensate in patients with stable and unstable cystic fibrosis. Thorax 2012; 67: 222-228.

Ibrahim B, Marsden P, Morris J, et al. Metabolomic analysis of exhaled breath condensate by NMR spectroscopy discriminates inflammatory phenotypes in asthma. Allergy 2013; 68: 1050-1056.

Carraro S, Giordano G, Reniero F, et al. Asthma severity in childhood and metabolomic profiling of breath condensate. Allergy 2013; 68: 110-117.

Montuschi P, Paris D, Montella S, et al. Nuclear magnetic resonance-based metabolomics discriminates primary ciliary dyskinesia from cystic fibrosis. Am J Respir Crit Care Med 2014; 190: 229-233.

Pleil JD, Angrish MM, Madden MC. Immunochemistry for high-throughput screening of human exhaled breath condensate (EBC) media: implementation of automated Quanterix SIMOA instrumentation. J Breath Res 2015; 9: 047108.

Pelclova D, Zdimal V, Kacer P, et al. Oxidative stress markers are elevated in exhaled breath condensate of workers exposed to nanoparticles during iron oxide pigment production. J Breath Res 2016; 10: 016004.

Montuschi P, Mores N, Trove A, et al. The electronic nose in respiratory medicine. Respiration 2013; 85: 72-84.

Fens N, de Nijs SB, Peters S, et al. Exhaled air molecular profiling in relation to inflammatory subtype and activity in COPD. Eur Respir J 2011; 38: 1301-1309.

van der Schee MP, Palmay R, Cowan JO, et al. Predicting steroid responsiveness in patients with asthma using exhaled breath profiling. Clin Exp Allergy 2013; 43: 1217-1225.

Fens N, van Rossum AG, Zanen P, et al. Subphenotypes of mild-to-moderate COPD by factor and cluster analysis of pulmonary function, CT imaging and breathomics in a population-based survey. COPD 2013; 10: 277-285.

Smolinska A, Hauschild AC, Fijten RR, et al. Current breathomics - a review on data pre-processing techniques and machine learning in metabolomics breath analysis. J Breath Res 2014; 8: 027105.

Chen R, Mias GI, Li-Pook-Than J, et al. Personal omics profiling reveals dynamic molecular and medical phenotypes. Cell 2012; 148: 1293-1307.

Auffray C, Adcock IM, Chung KF, et al. An integrative systems biology approach to understanding pulmonary diseases. Chest 2010; 137: 1410-1416.

Wheelock CE, Goss VM, Balgoma D, et al. Application of 'omics technologies to biomarker discovery in inflammatory lung diseases. Eur Respir J 2013; 42: 802-825.

Wagener AH, Yick CY, Brinkman P, et al. Toward composite molecular signatures in the phenotyping of asthma. Ann Am Thorac Soc 2013; 10: Suppl., S197-S205.

Sung J, Wang Y, Chandrasekaran S, et al. Molecular signatures from omics data: from chaos to consensus. Biotechnol J 2012; 7: 946-957.

Broadhurst D, Kell D. Statistical strategies for avoiding false discoveries in metabolomics and related experiments. Metabolomics 2006; 2: 171-196. explanation and elaboration. BMC Med 2013; 11: 220

de Lacy Costello B, Amann A, Al-Kateb H, et al. A review of the volatiles from the healthy human body. J Breath Res 2014; 8: 014001.

Pleil JD, Stiegel MA. Evolution of environmental exposure science: using breath-borne biomarkers for "discovery" of the human exposome. Anal Chem 2013; 85: 9984-9990.

Haick H, Broza YY, Mochalski P, et al. Assessment, origin, and implementation of breath volatile cancer markers. Chem Soc Rev 2014; 43: 1423-1449.

King J, Kupferthaler A, Frauscher B, et al. Measurement of endogenous acetone and isoprene in exhaled breath during sleep. Physiol Meas 2012; 33: 413-428.

Modak AS. Stable isotope breath tests in clinical medicine: a review. J Breath Res 2007; 1: 014003. 247: 272-278.

Bikov A, Lázár Z, Horvath I. Established methodological issues in electronic nose research: how far are we from using these instruments in clinical settings of breath analysis? J Breath Res 2015; 9: 034001.

King J, Unterkofler K, Teschl G, et al. A modeling-based evaluation of isothermal rebreathing for breath gas analyses of highly soluble volatile organic compounds. J Breath Res 2012; 6: 016005.

Dragonieri S, Schot R, Mertens BJ, et al. An electronic nose in the discrimination of patients with asthma and controls. J Allergy Clin Immunol 2007; 120: 856-862.

Miekisch W, Schubert JK, Noeldge-Schomburg GF. Diagnostic potential of breath analysis-focus on volatile organic compounds. Clin Chim Acta 2004; 347: 25-39.

Montuschi P, Santonico M, Mondino C, et al. Diagnostic performance of an electronic nose, fractional exhaled nitric oxide, and lung function testing in asthma. Chest 2010; 137: 790-796.

Hakim M, Billan S, Tisch U, et al. Diagnosis of head-and-neck cancer from exhaled breath. Br J Cancer 2011; 104: 1649-1655.

de Vries R, Brinkman P, van der Schee MP, et al. Integration of electronic nose technology with spirometry: validation of a new approach for exhaled breath analysis. J Breath Res 2015; 9: 046001.

polyvinyl fluoride Tedlar ${ }^{\circledR}$ bags. Anal Chim Acta 2012; 712: 162-167.

Mochalski P, Wzorek B, Sliwka I, et al. Suitability of different polymer bags for storage of volatile sulphur compounds relevant to breath analysis. J Chromatogr B Analyt Technol Biomed Life Sci 2009; 877: $189-196$. Peng G, Tisch U, Adams O, et
Nat Nanotechnol 2009; 4: 669-673.

Kamboures MA, Blake DR, Cooper DM, et al. Breath sulfides and pulmonary function in cystic fibrosis. Proc Natl Acad Sci USA 2005; 102: 15762-15767.

van der Schee MP, Fens N, Brinkman P, et al. Effect of transportation and storage using sorbent tubes of exhaled breath samples on diagnostic accuracy of electronic nose analysis. J Breath Res 2013; 7: 016002.

Rock F, Barsan N, Weimar U. Electronic nose: current status and future trends. Chem Rev 2008; 108: 705-725. 
Gawłowski J, Gierczak T, Jezo A, et al. Adsorption of water vapour in the solid sorbents used for the sampling of volatile organic compounds. Analyst 1999; 124: 1553-1558.

Bikov A, Hernadi M, Korosi BZ, et al. Expiratory flow rate, breath hold and anatomic dead space influence electronic nose ability to detect lung cancer. BMC Pulm Med 2014; 14: 202.

Boshier PR, Priest OH, Hanna GB, et al. Influence of respiratory variables on the on-line detection of exhaled trace gases by PTR-MS. Thorax 2011; 66: 919-920.

119 Bikov A, Paschalaki K, Logan-Sinclair R, et al. Standardised exhaled breath collection for the measurement of exhaled volatile organic compounds by proton transfer reaction mass spectrometry. BMC Pulm Med 2013; 13 : 43.

Larstad MA, Toren K, Bake B, et al. Determination of ethane, pentane and isoprene in exhaled air-effects of breath-holding, flow rate and purified air. Acta Physiol (Oxf) 2007; 189: 87-98.

121 Thekedar B, Oeh U, Szymczak W, et al. Influences of mixed expiratory sampling parameters on exhaled volatile organic compound concentrations. J Breath Res 2011; 5: 016001.

122 Lazar Z, Fens N, van der Maten J, et al. Electronic nose breathprints are independent of acute changes in airway caliber in asthma. Sensors (Basel) 2010; 10: 9127-9138.

123 Smolinska A, Klaassen EM, Dallinga JW, et al. Profiling of volatile organic compounds in exhaled breath as a strategy to find early predictive signatures of asthma in children. PLoS One 2014; 9: e95668.

124 van der Schee MP, Hashimoto S, Schuurman AC, et al. Altered exhaled biomarker profiles in children during and after rhinovirus-induced wheeze. Eur Respir J 2015; 45: 440-448.

125 Bos LD, Wang Y, Weda H, et al. A simple breath sampling method in intubated and mechanically ventilated critically ill patients. Respir Physiol Neurobiol 2014; 191: 67-74.

126 Trefz P, Schmidt M, Oertel P, et al. Continuous real time breath gas monitoring in the clinical environment by proton-transfer-reaction-time-of-flight-mass spectrometry. Anal Chem 2013; 85: 10321-10329.

127 Baranska A, Tigchelaar E, Smolinska A, et al. Profile of volatile organic compounds in exhaled breath changes as a result of gluten-free diet. J Breath Res 2013; 7: 037104.

128 Jones AW. Breath-acetone concentrations in fasting healthy men: response of infrared breath-alcohol analyzers. J Anal Toxicol 1987; 11: 67-69.

129 Mattison LK, Fourie J, Hirao Y, et al. The uracil breath test in the assessment of dihydropyrimidine dehydrogenase activity: pharmacokinetic relationship between expired ${ }^{13} \mathrm{CO}_{2}$ and plasma $\left[2-{ }^{13} \mathrm{C}\right]$ dihydrouracil. Clin Cancer Res 2006; 12: 549-555.

130 Antus B, Barta I, Horvath I, et al. Relationship between exhaled nitric oxide and treatment response in COPD patients with exacerbations. Respirology 2010; 15: 472-477.

131 Greenwald R, Ferdinands JM, Teague WG. Ionic determinants of exhaled breath condensate $\mathrm{pH}$ before and after exercise in adolescent athletes. Pediatr Pulmonol 2009; 44: 768-777.

132 Bikov A, Lazar Z, Schandl K, et al. Exercise changes volatiles in exhaled breath assessed by an electronic nose. Acta Physiol Hung 2011; 98: 321-328.

133 King J, Kupferthaler A, Unterkofler K, et al. Isoprene and acetone concentration profiles during exercise on an ergometer. J Breath Res 2009; 3: 027006.

134 Fens N, Zwinderman AH, van der Schee MP, et al. Exhaled breath profiling enables discrimination of chronic obstructive pulmonary disease and asthma. Am J Respir Crit Care Med 2009; 180: 1076-1082.

135 Cheng ZJ, Warwick G, Yates DH, et al. An electronic nose in the discrimination of breath from smokers and non-smokers: a model for toxin exposure. J Breath Res 2009; 3: 036003.

136 Fens N, Douma RA, Sterk PJ, et al. Breathomics as a diagnostic tool for pulmonary embolism. J Thromb Haemost 2010; 8: 2831-2833.

137 van der Schee MP, Paff T, Brinkman P, et al. Breathomics in lung disease. Chest 2015; 147: $224-231$.

138 David S, Patrik Š, Jens H, et al. Mass spectrometry for real-time quantitative breath analysis. J Breath Res 2014; 8: 027101.

139 Bazemore RA, Feng J, Cseke L, et al. Biomedically important pathogenic fungi detection with volatile biomarkers. J Breath Res 2012; 6: 016002.

140 Bos LD, Sterk PJ, Schultz MJ. Volatile metabolites of pathogens: a systematic review. PLoS Pathog 2013; 9: e1003311

141 Boots AW, Smolinska A, van Berkel JJ, et al. Identification of microorganisms based on headspace analysis of volatile organic compounds by gas chromatography-mass spectrometry. J Breath Res 2014; 8: 027106.

142 Whiteson KL, Meinardi S, Lim YW, et al. Breath gas metabolites and bacterial metagenomes from cystic fibrosis airways indicate active $\mathrm{pH}$ neutral 2,3-butanedione fermentation. ISME J 2014; 8: 1247-1258.

143 Ibrahim B, Basanta M, Cadden P, et al. Non-invasive phenotyping using exhaled volatile organic compounds in asthma. Thorax 2011; 66: 804-809.

144 van de Kant KD, van Berkel JJ, Jobsis Q, et al. Exhaled breath profiling in diagnosing wheezy preschool children. Eur Respir J 2013; 41: 183-188.

145 Dallinga JW, Robroeks CM, van Berkel JJ, et al. Volatile organic compounds in exhaled breath as a diagnostic tool for asthma in children. Clin Exp Allergy 2010; 40: 68-76.

146 Hakim M, Broza YY, Barash O, et al. Volatile organic compounds of lung cancer and possible biochemical pathways. Chem Rev 2012; 112: 5949-5966.

147 Fens N, Roldaan AC, van der Schee MP, et al. External validation of exhaled breath profiling using an electronic nose in the discrimination of asthma with fixed airways obstruction and chronic obstructive pulmonary disease. Clin Exp Allergy 2011; 41: 1371-1378.

148 van de Kant KD, van der Sande LJ, Jobsis Q, et al. Clinical use of exhaled volatile organic compounds in pulmonary diseases: a systematic review. Respir Res 2012; 13: 117.

149 Fens N, van der Schee MP, Brinkman P, et al. Exhaled breath analysis by electronic nose in airways disease. Established issues and key questions. Clin Exp Allergy 2013; 43: 705-715.

150 D'Amico A, Di Natale C, Falconi C, et al. Detection and identification of cancers by the electronic nose. Expert Opin Med Diagn 2012; 6: 175-185.

151 Di Natale C, Paolesse R, Martinelli E, et al. Solid-state gas sensors for breath analysis: a review. Anal Chim Acto 2014; 824: 1-17.

152 Inyawilert K, Wisitsora-at A, Tuantranont A, et al. Ultra-rapid VOCs sensors based on sparked- $\mathrm{In}_{2} \mathrm{O}_{3}$ sensing films. Sens Actuators B Chem 2014; 192: 745-754. 
Kumar B, Park Y, Castro M, et al. Fine control of carbon nanotubes-polyelectrolyte sensors sensitivity by electrostatic layer by layer assembly (eLbL) for the detection of volatile organic compounds (VOC). Talanta 2012; 88: 396-402.

Incalzi RA, Pennazza G, Scarlata S, et al. Reproducibility and respiratory function correlates of exhaled breath fingerprint in chronic obstructive pulmonary disease. PLoS One 2012; 7: e45396.

Mochalski P, King J, Unterkofler K, et al. Stability of selected volatile breath constituents in Tedlar, Kynar and Flexfilm sampling bags. Analyst 2013; 138: 1405-1418.

Basanta M, Ibrahim B, Dockry R, et al. Exhaled volatile organic compounds for phenotyping chronic obstructive pulmonary disease: a cross-sectional study. Respir Res 2012; 13: 72.

Cohen-Kaminsky S, Nakhleh M, Perros F, et al. A proof of concept for the detection and classification of pulmonary arterial hypertension through breath analysis with a sensor array. Am J Respir Crit Care Med 2013; 188: 756-759.

Marom O, Nakhoul F, Tisch U, et al. Gold nanoparticle sensors for detecting chronic kidney disease and disease progression. Nanomedicine (Lond) 2012; 7: 639-650.

Wang Y, Hu Y, Wang D, et al. The analysis of volatile organic compounds biomarkers for lung cancer in exhaled breath, tissues and cell lines. Cancer Biomark 2012; 11: 129-137.

Pennazza G, Santonico M, Agrò AF. Narrowing the gap between breathprinting and disease diagnosis, a sensor perspective. Sens Actuators B Chem 2013; 179: 270-275.

Phillips M, Cataneo RN, Chaturvedi A, et al. Detection of an extended human volatome with comprehensive two-dimensional gas chromatography time-of-flight mass spectrometry. PLoS One 2013; 8: e75274.

an Berkel J, Dallinga J, Möller G, et al. Development of accurate classification method based on the analysis of volatile organic compounds from human exhaled air. J Chromatogr B 2008; 861: 101-107.

Santonico M, Pennazza G, Capuano R, et al. Electronic noses calibration procedure in the context of a multicentre medical study. Sens Actuators B Chem 2012; 173: 555-561.

Wolf A, Baumbach JI, Kleber A, et al. Multi-capillary column-ion mobility spectrometer (MCC-IMS) breath analysis in ventilated rats: a model with the feasibility of long-term measurements. J Breath Res 2014; 8: 016006.

Kanu AB, Hill HH Jr. Ion mobility spectrometry detection for gas chromatography. J Chromatogr A 2008; 1177: $12-27$.

Zrodnikov Y, Davis CE. The highs and lows of FAIMS: predictions and future trends for high field asymmetric waveform ion mobility spectrometry. J Nanomed Nanotechnol 2012; 3: 109e.

Smith D, Španěl P. Selected ion flow tube mass spectrometry (SIFT-MS) for on-line trace gas analysis. Mass Spectrom Rev 2005; 24: 661-700.

Kumar S, Huang J, Abbassi-Ghadi N, et al. Selected ion flow tube mass spectrometry analysis of exhaled breath for volatile organic compound profiling of esophago-gastric cancer. Anal Chem 2013; 85: 6121-6128.

Filipiak W, Sponring A, Filipiak A, et al. TD-GC-MS analysis of volatile metabolites of human lung cancer and normal cells in vitro. Cancer Epidemiol Biomarkers Prev 2010; 19: 182-195.

Amorim LC, Carneiro JP, Cardeal ZL. An optimized method for determination of benzene in exhaled air by gas chromatography-mass spectrometry using solid phase microextraction as a sampling technique. J Chromatography B 2008; 865: 141-146. spectrometry: status and perspectives. Metabolomics 2011; 7: 307-328.

Goodacre R, Broadhurst D, Smilde AK, et al. Proposed minimum reporting standards for data analysis in metabolomics. Metabolomics 2007; 3: 231-241.

Kischkel S, Miekisch W, Sawacki A, et al. Breath biomarkers for lung cancer detection and assessment of smoking related effects-confounding variables, influence of normalization and statistical algorithms. Clin Chim Acta 2010; 411: 1637-1644.

Hastie T, Tibshirani R, Friedman J. The Elements of Statistical Learning. Data Mining, Inference, and Prediction. 2nd Edn. New York, Springer, 2009. http://statweb.stanford.edu/ tibs/ElemStatLearn/.

Gromski PS, Correa E, Vaughan AA, et al. A comparison of different chemometrics approaches for the robust classification of electronic nose data. Anal Bioanal Chem 2014; 406: 7581-7590. explanation and elaboration. Ann Intern Med 2003; 138: W1-W12.

Schulz KF, Altman DG, Moher D, et al. CONSORT 2010 statement: updated guidelines for reporting parallel group randomised trials. BMJ 2010; 340: c332.

Collins GS, Reitsma JB, Altman DG, et al. Transparent reporting of a multivariable prediction model for individual prognosis or diagnosis (TRIPOD): the TRIPOD statement. Ann Intern Med 2015; 162: 55-63.

Pencina MJ, D'Agostino RB Sr, D’Agostino RB Jr, et al. Evaluating the added predictive ability of a new marker: from area under the ROC curve to reclassification and beyond. Stat Med 2008; 27: 157-172; discussion $207-112$.

Tarnoki DL, Bikov A, Tarnoki AD, et al. Lack of heritability of exhaled volatile compound pattern: an electronic nose twin study. J Breath Res 2014; 8: 016001.

Van Berkel JJ, Dallinga JW, Moller GM, et al. A profile of volatile organic compounds in breath discriminates COPD patients from controls. Respir Med 2010; 104: 557-563.

Antus B, Barta I, Czebe K, et al. Analysis of cytokine pattern in exhaled breath condensate of lung transplant recipients with bronchiolitis obliterans syndrome. Inflamm Res 2010; 59: 83-86.

Bos LD, Weda H, Wang Y, et al. Exhaled breath metabolomics as a noninvasive diagnostic tool for acute respiratory distress syndrome. Eur Respir J 2014; 44: 188-197.

BMC Pulm Med 2014; 14: 72 .
Beopold

Leopold JH, Bos LD, Sterk PJ, et al. Comparison of classification methods in breath analysis by electronic nose. J Breath Res 2015; 9: 046002.

Sethi S, Nanda R, Chakraborty T. Clinical application of volatile organic compound analysis for detecting infectious diseases. Clin Microbiol Rev 2013; 26: 462-475.

Robroeks CM, van Berkel JJ, Jobsis Q, et al. Exhaled volatile organic compounds predict exacerbations of childhood asthma in a 1-year prospective study. Eur Respir J 2013; 42: 98-106. 
Pennazza G, Santonico M, Incalzi RA, et al. Measure chain for exhaled breath collection and analysis: a nove approach suitable for frail respiratory patients. Sens Actuators B Chem 2014; 204: 578-587.

Boots AW, Bos LD, van der Schee MP, et al. Exhaled molecular fingerprinting in diagnosis and monitoring: validating volatile promises. Trends Mol Med 2015; 21: 633-644.

Herbig J, Beauchamp J. Towards standardization in the analysis of breath gas volatiles. J Breath Res 2014; 8: 037101. Horváth I, Lázár Z, Gyulai N, et al. Exhaled biomarkers in lung cancer. Eur Respir J 2009; 34: 261-275.

Bikov A, Pako J, Kovacs D, et al. Exhaled breath volatile alterations in pregnancy assessed with electronic nose. Biomarkers 2011; 16: 476-484.

Schmidt K, Podmore I. Current challenges in volatile organic compounds analysis as potential biomarkers of cancer. J Biomarker 2015; 2015: 981458.

van Mastrigt E, de Jongste JC, Pijnenburg MW. The analysis of volatile organic compounds in exhaled breath and biomarkers in exhaled breath condensate in children - clinical tools or scientific toys? Clin Exp Allergy 2015; 45: $1170-1188$.

Kovacs D, Bikov A, Losonczy G, et al. Follow up of lung transplant recipients using an electronic nose. J Breath Res 2013; 7: 017117.

Meyer N, Dallinga JW, Nuss SJ, et al. Defining adult asthma endotypes by clinical features and patterns of volatile organic compounds in exhaled air. Respir Res 2014; 15: 136.

Antus B, Kardos Z. Oxidative stress in COPD: molecular background and clinical monitoring. Curr Med Chem 2015; 22: 627-650.

Benedek P, Lázár Z, Bikov A, et al. Exhaled biomarker pattern is altered in children with obstructive sleep apnoea syndrome. Int J Pediatr Otorhinolaryngol 2013; 77: 1244-1247.

Kunos L, Bikov A, Lazar Z, et al. Evening and morning exhaled volatile compound patterns are different in obstructive sleep apnoea assessed with electronic nose. Sleep Breath 2015; 19: 247-253.

Dragonieri S, Porcelli F, Longobardi F, et al. An electronic nose in the discrimination of obese patients with and without obstructive sleep apnoea. J Breath Res 2015; 9: 026005.

Antonelli Incalzi R, Pennazza G, Scarlata S, et al. Comorbidity modulates non invasive ventilation-induced changes in breath print of obstructive sleep apnea syndrome patients. Sleep Breath 2015; 19: 623-630.

Hicks LC, Huang J, Kumar S, et al. Analysis of exhaled breath volatile organic compounds in inflammatory bowel disease: a pilot study. J Crohns Colitis 2015; 9: 731-737.

Bodelier AG, Smolinska A, Baranska A, et al. volatile organic compounds in exhaled air as novel marker for disease activity in Crohn's disease: a metabolomic approach. Inflamm Bowel Dis 2015; 21: 1776-1785.

Eng K, Alkhouri N, Cikach F, et al. Analysis of breath volatile organic compounds in children with chronic liver disease compared to healthy controls. J Breath Res 2015; 9: 026002

de Boer NK, de Meij TG, Oort FA, et al. The scent of colorectal cancer: detection by volatile organic compound analysis. Clin Gastroenterol Hepatol 2014; 12: 1085-1089.

Nakhleh MK, Badarny S, Winer R, et al. Distinguishing idiopathic Parkinson's disease from other parkinsonian syndromes by breath test. Parkinsonism Relat Disord 2015; 21: 150-153.

Boshuizen M, Leopold JH, Zakharkina T, et al. Levels of cytokines in broncho-alveolar lavage fluid, but not in plasma, are associated with levels of markers of lipid peroxidation in breath of ventilated ICU patients. $J$ Breath Res 2015; 9: 036010.

Madureira J, Paciência I, Ramos E, et al. Children's health and indoor air quality in primary schools and homes in Portugal-study design. Toxicol Environ Health A 2015; 78: 915-930.

Kwak J, Geier BA, Fan M, et al. Detection of volatile organic compounds indicative of human presence in the air. J Sep Sci 2015; 38: 2463-2469.

Hauschild AC, Frisch T, Baumbach JI, et al. Carotta: revealing hidden confounder markers in metabolic breath profiles. Metabolites 2015; 5: 344-363.

Figueroa JA, Mansoor JK, Allen RP, et al. Exhaled volatile organic compounds in individuals with a history of high altitude pulmonary edema and varying hypoxia-induced responses. J Breath Res 2015; 9: 026004.

McWilliams A, Beigi P, Srinidhi A, et al. Sex and smoking status effects on the early detection of early lung cancer in high-risk smokers using an electronic nose. IEEE Trans Biomed Eng 2015; 62: 2044-2054.

Moritz F, Janicka M, Zygler A, et al. The compositional space of exhaled breath condensate and its link to the human breath volatilome. J Breath Res 2015; 9: 027105.

breath. J Breath Res 2014; 8: 037102

Kopczynski D, Rahmann S. An online peak extraction algorithm for ion mobility spectrometry data. Algorithms Mol Biol 2015; 10: 17.

Ligor T, Pater $€$, Buszewski B. Application of an artificial neural network model for selection of potential lung cancer biomarkers. J Breath Res 2015; 9: 027106. screening programmes $\dagger$. Eur J Cardiothorac Surg 2016; 49: 1112-1117. from exhaled breath. Nano Lett 2015; 15: 7023-7028.

Fink T, Albrecht FW, Maurer F, et al. Exhalation pattern changes during fasting and low dose glucose treatment in rats. Anal Bioanal Chem 2015; 407: 3763-3773.

Fischer S, Trefz P, Bergmann A, et al. Physiological variability in volatile organic compounds (VOCs) in exhaled breath and released from faeces due to nutrition and somatic growth in a standardized caprine animal model. J Breath Res 2015; 9: 027108.

Albrecht FW, Hüppe T, Fink T, et al. Influence of the respirator on volatile organic compounds: an animal study in rats over 24 hours. J Breath Res 2015; 9: 016007.

Sibila O, Garcia-Bellmunt L, Giner J, et al. Identification of airway bacterial colonization by an electronic nose in chronic obstructive pulmonary disease. Respir Med 2014; 108: 1608-1614.

Shestivska V, Dryahina K, Nunvář J, et al. Quantitative analysis of volatile metabolites released in vitro by bacteria of the genus Stenotrophomonas for identification of breath biomarkers of respiratory infection in cystic fibrosis. J Breath Res 2015; 9: 027104. 
Högman M. Extended NO analysis in health and disease. J Breath Res 2012; 6: 047103.

Berhane K, Zhang Y, Salam MT, et al. Longitudinal effects of air pollution on exhaled nitric oxide: the Children's Health Study. Occup Environ Med 2014; 71: 507-513.

Flamant-Hulin M, Caillaud D, Sacco P, et al. Air pollution and increased levels of fractional exhaled nitric oxide in children with no history of airway damage. J Toxicol Environ Health A 2009; 73: 272-283.

La Grutta S, Ferrante G, Malizia V, et al. Environmental effects on fractional exhaled nitric oxide in allergic children. J Allergy (Cairo) 2012; 2012: 916926.

Karitonov S, Alving K, Barnes PJ. Exhaled and nasal nitric oxide measurements: recommendations. The European Respiratory Society Task Force. Eur Respir J 1997; 10: 1683-1693.

Recommendations for standardized procedures for the on-line and off-line measurement of exhaled lower respiratory nitric oxide and nasal nitric oxide in adults and children-1999. This official statement of the American Thoracic Society was adopted by the ATS Board of Directors, July 1999. Am J Respir Crit Care Med 1999; 160: 2104-2117.

Petsky HL, Cates CJ, Li A, et al. Tailored interventions based on exhaled nitric oxide versus clinical symptoms for asthma in children and adults. Cochrane Database Syst Rev 2009; 4: CD006340.

Reddel HK, Taylor DR, Bateman ED, et al. An official American Thoracic Society/European Respiratory Society statement: asthma control and exacerbations: standardizing endpoints for clinical asthma trials and clinical practice. Am J Respir Crit Care Med 2009; 180: 59-99.

Högman M, Malinovschi A, Norbäck D, et al. Added value with extended NO analysis in atopy and asthma. Clin Physiol Funct Imaging 2011; 31: 294-299.

Ludviksdottir D, Janson C, Högman M, et al. Exhaled nitric oxide and its relationship to airway responsiveness and atopy in asthma. BHR-Study Group. Respir Med 1999; 93: 552-556.

Ricciardolo FL, Sorbello V, Ciprandi G. FeNO as biomarker for asthma phenotyping and management. Allergy Asthma Proc 2015; 36: 1-8.

Wenzel SE. Emergence of biomolecular pathways to define novel asthma phenotype. Type-2 immunity and beyond. Am J Respir Cell MolBiol 2016; 55: 1-4.

Essat M, Harnan S, Gomersall T, et al. Fractional exhaled nitric oxide for the management of asthma in adults: systematic review. Eur Respir J 2016; 47: 751-768.

Kethimäki L, Csonka P, Mäkinen E, et al. Predictive value of exhaled nitric oxide in the management of asthma: a systematic review. Eur Respir J 2016; 48: 706-714.

Deykin A, Halpern O, Massaro AF, et al. Expired nitric oxide after bronchoprovocation and repeated spirometry in patients with asthma. Am J Respir Crit Care Med 1998; 157: 769-775.

Högman M, Drca N, Ehrstedt C, et al. Exhaled nitric oxide partitioned into alveolar, lower airways and nasal contributions. Respir Med 2000; 94: 985-991. 017104 . Maniscalco M, Vitale C, Vatrella A, et al. Fractional exhaled nitric oxide-measuring devices: technology update. Med Device (Auckl) 2016; 9: 151-160. comparison with chemiluminescent and electrochemical sensors. J Biomed Opt 2012; 17: 017003.

Antus B, Horvath I, Barta I. Assessment of exhaled nitric oxide by a new hand-held device. Respir Med 2010; 104: $1377-1380$.

Kapande KM, McConaghy LA, Douglas I, et al. Comparative repeatability of two handheld fractional exhaled nitric oxide monitors. Pediatr Pulmonol. 2012; 47: 546-550.

Cattoni I, Guarnieri G, Tosetto A, et al. Mechanisms of decrease in fractional exhaled nitric oxide during acute bronchoconstriction. Chest 2013; 143: 1269-1276.

Haccuria A, Michils A, Michiels S, et al. Exhaled nitric oxide: a biomarker integrating both lung function and airway inflammation changes. J Allergy Clin Immunol 2014; 134: 554-559.

Saito J, Gibeon D, Macedo P, et al. Domiciliary diurnal variation of exhaled nitric oxide fraction for asthma control. Eur Respir J 2014; 43: 474-484.

Heijkenskjöld-Rentzhog C, Alving K, Kalm-Stephens P, et al. The fraction of NO in exhaled air and estimates of alveolar NO in adolescents with asthma: methodological aspects. Pediatr Pulmonol 2012; 47: 941-949.

Piirila P, Rouhos A, Kainu A, et al. Reduction of fractional exhaled nitric oxide (FENO) and its variation by mouth wash. Scand J Clin Lab Invest 2012; 72: 253-257.

Jacinto T, Malinovschi A, Janson C, et al. Evolution of exhaled nitric oxide levels throughout development and aging of healthy humans. J Breath Res 2015; 9: 036005.

never-smokers. Chest 2007; 131: 1852-1856.

Högman M, Lafih J, Meriläinen P, et al. Extended NO analysis in a healthy subgroup of a random sample from a Swedish population. Clin Physiol Funct Imaging 2009; 29: 18-23.

2006; 7: 94

Dweik RA, Boggs PB, Erzurum SC, et al. An official ATS clinical practice guideline: interpretation of exhaled nitric oxide levels (FENO) for clinical applications. Am J Respir Crit Care Med 2011; 184: 602-615.

Bjermer L, Alving K, Diamant Z, et al. Current evidence and future research needs for FeNO measurement in respiratory diseases. Respir Med 2014; 108: 830-841.

Högman $M$, Meriläinen P. Guidance for a personal target value of $\mathrm{F}_{\mathrm{E}} \mathrm{NO}$ in allergic asthma: case report and theoretical example. Ups J Med Sci 2013; 118: 59-61.

Thornadtsson A, Neerincx AH, Högman $\mathrm{M}$, et al. Extended $\mathrm{NO}$ analysis may improve personalized anti-inflammatory treatment in asthmatic children with intermediate $\mathrm{F}_{\mathrm{E}} \mathrm{NO}_{50}$. J Breath Res 2015; 9: 047114 .

Lundberg JON, Rinder J, Weitzberg E, et al. Nasally exhaled nitric oxide in humans originates mainly in the paranasal sinuses. Acta Physiol Scand 1994; 152: 431-432.

Lundberg JO, Weitzberg E, Nordvall SL, et al. Primarily nasal origin of exhaled nitric oxide and absence in Kartagener's syndrome. Eur Respir J 1994; 7: 1501-1504. 
Collins SA, Gove K, Walker W, et al. Nasal nitric oxide screening for primary ciliary dyskinesia: systematic review and meta-analysis. Eur Respir J 2014; 44: 1589-1599.

Takeno S, Noda N, Hirakawa K. Measurements of nasal fractional exhaled nitric oxide with a hand-held device in patients with allergic rhinitis: relation to cedar pollen dispersion and laser surgery. Allergol Int 2012; 61: 93-100.

Palm JP, Graf P, Lundberg JO, et al. Characterization of exhaled nitric oxide: introducing a new reproducible method for nasal nitric oxide measurements. Eur Respir J 2000; 16: 236-241.

263 Silkoff PE, Chatkin J, Qian W, et al. Nasal nitric oxide: a comparison of measurement techniques. Amer J Rhinol 1999; 13: 169-178.

264 Leigh MW, Hazucha MJ, Chawla KK, et al. Standardizing nasal nitric oxide measurement as a test for primary ciliary dyskinesia. Ann Am Thorac Soc 2013; 10: 574-581.

265 Weitzberg E, Lundberg JO. Humming greatly increases nasal nitric oxide. Am J Respir Crit Care Med 2002; 166: $144-145$.

266 Bartley J, Fergusson W, Moody A, et al. Normal adult values, diurnal variation, and repeatability of nasal nitric oxide measurement. Am J Rhinol 1999; 13: 401-405.

267 Struben VM, Wieringa MH, Mantingh CJ, et al. Silent and humming nasal NO measurements in adults aged 18-70 years. Eur J Clin Invest 2005; 35: 653-657.

268 Struben VM, Wieringa MH, Mantingh CJ, et al. Nasal NO: normal values in children age 6 through to 17 years. Eur Respir J 2005; 26: 453-457.

269 Marthin JK, Nielsen KG. Choice of nasal nitric oxide technique as first-line test for primary ciliary dyskinesia. Eur Respir J 2011; 37: 559-565.

270 Tsoukias NM, George SC. A two-compartment model of pulmonary nitric oxide exchange dynamics. J Appl Physiol 1998; 85: 653-666.

271 George SC, Högman M, Permutt S, et al. Modeling pulmonary nitric oxide exchange. J Appl Physiol 2004; 96: 831-839.

Condorelli P, Shin HW, Aledia AS, et al. A simple technique to characterize proximal and peripheral nitric oxide exchange using constant flow exhalations and an axial diffusion model. J Appl Physiol 2007; 102: 417-425.

Eckel SP, Linn WS, Berhane K, et al. Estimation of parameters in the two-compartment model for exhaled nitric oxide. PLoS One 2014; 9: e85471.

274 Högman M, Holmkvist T, Wegener T, et al. Extended NO analysis applied to patients with COPD, allergic asthma and allergic rhinitis. Respir Med 2002; 96: 24-30.

275 Högman M, Thornadtsson A, Hedenstierna G, et al. A practical approach to the theoretical models to calculate NO parameters of the respiratory system. J Breath Res 2014; 8: 016002.

276 Roy K, Borrill ZL, Starkey C, et al. Use of different exhaled nitric oxide multiple flow rate models in COPD. Eur Respir J 2007; 29: 651-659.

277 Chladkova J, Senkerik M, Havlinova Z, et al. Alveolar concentration and bronchial flux of nitric oxide: two linear modeling methods evaluated in children and adolescents with allergic rhinitis and atopic asthma. Pediatr Pulmonol 2012; 47: 1070-1079.

278 Kerckx Y, Michils A, Van Muylem A. Airway contribution to alveolar nitric oxide in healthy subjects and stable asthma patients. J Appl Physiol 2008; 104: 918-924.

279 Heijkenskjöld-Rentzhog C, Nordvall L, Janson C, et al. Alveolar and exhaled NO in relation to asthma characteristics - effects of correction for axial diffusion. Allergy 2014; 69: 1102-1111.

280 Sepponen A, Lehtimäki L, Huhtala H, et al. Alveolar and bronchial nitric oxide output in healthy children. Pediatr Pulmonol 2008; 43: 1242-1248.

281 Paraskakis E, Brindicci C, Fleming L, et al. Measurement of bronchial and alveolar nitric oxide production in normal children and children with asthma. Am J Respir Crit Care Med 2006; 174: 260-267.

282 Mahut B, Trinquart L, Le Bourgeois M, et al. Multicentre trial evaluating alveolar NO fraction as a marker of asthma control and severity. Allergy 2010; 65: 636-644.

283 Robroeks CM, van Vliet D, Hendriks HJ, et al. Feasibility of exhaled nitric oxide measurements at various flow rates in children with asthma. Pediatr Allergy Immunol 2010; 21: e222-e228.

284 Puckett JL, Taylor RW, Leu SY, et al. Clinical patterns in asthma based on proximal and distal airway nitric oxide categories. Respir Res 2010; 11: 47.

285 Mahut B, Delacourt C, Zerah-Lancner F, et al. Increase in alveolar nitric oxide in the presence of symptoms in childhood asthma. Chest 2004; 125: 1012-1018.

286 Pedroletti C, Högman M, Meriläinen P, et al. Nitric oxide airway diffusing capacity and mucosal concentration in asthmatic schoolchildren. Pediatr Res 2003; 54: 496-501.

287 Taylor DR, Palmay R, Cowan JO, et al. Long term performance characteristics of an electrochemical nitric oxide analyser. Respir Med 2011; 105: 211-217.

288 Hemmingsson T, Linnarsson D, Gambert R. Novel hand-held device for exhaled nitric oxide-analysis in research and clinical applications. J Clin Monit Comput 2004; 18: 379-387.

289 Hunter GW, Xu JC, Biaggi-Labiosa AM, et al. Smart sensor systems for human health breath monitoring applications. J Breath Res 2011; 5: 037111.

290 McCurdy MR, Bakhirkin Y, Wysocki G, et al. Performance of an exhaled nitric oxide and carbon dioxide sensor using quantum cascade laser-based integrated cavity output spectroscopy. J Biomed Opt 2007; 12 : 034034.

291 Mandon J, Hogman M, Merkus PJ, et al. Exhaled nitric oxide monitoring by quantum cascade laser: comparison with chemiluminescent and electrochemical sensors. J Biomed Opt 2012; 17: 017003.

292 Silva ML, Sonnenfroh DM, Rosen DI, et al. Integrated cavity output spectroscopy measurements of NO levels in breath with a pulsed room-temperature QCL. Appl Phys B 2005; 81: 705-710.

293 Lewicki R, Doty JH 3rd, Curl RF, et al. Ultrasensitive detection of nitric oxide at 5.33 microm by using external cavity quantum cascade laser-based Faraday rotation spectroscopy. Proc Natl Acad Sci USA 2009; 106: 12587-12592.

294 Shorter JH, Nelson DD, McManus JB, et al. Clinical study of multiple breath biomarkers of asthma and COPD $\left(\mathrm{NO}, \mathrm{CO}_{2}, \mathrm{CO}\right.$ and $\mathrm{N}_{2} \mathrm{O}$ ) by infrared laser spectroscopy. J Breath Res 2011; 5: 037108 .

295 Almstrand AC, Ljungström E, Lausmaa J, et al. Airway monitoring by collection and mass spectrometric analysis of exhaled particles. Anal Chem 2009; 81: 662-668. 
Schwarz K, Biller H, Windt $\mathrm{H}$, et al. Characterization of exhaled particles from the healthy human lung-a systematic analysis in relation to pulmonary function variables. J Aeros Med Pulm Drug Delivery 2010; 23: 371-379.

Schwarz K, Biller H, Windt H, et al. Characterization of exhaled particles from the human lungs in airway obstruction. J Aerosol Med Pulm Drug Deliv 2015; 28: 52-58.

298 Almstrand AC, Bake B, Ljungström E, et al. Effect of airway opening on production of exhaled particles. J Appl Physiol 2010; 108: 584-588.

299 Holmgren H, Gerth E, Ljungström E, et al. Effects of breath holding at low and high lung volumes on amount of exhaled particles. Respir Physiol Neurobiol 2013; 185: 228-234.

300 Almstrand AC, Josefson M, Bredberg A, et al. TOF-SIMS analysis of exhaled particles from patients with asthma and healthy controls. Eur Respir J 2012; 39: 59-66.

301 Bredberg A, Josefson M, Almstrand AC, et al. Comparison of exhaled endogenous particles from smokers and non-smokers using multivariate analysis. Respiration 2013; 86: 135-142.

302 Fessler MB, Summer RS. Surfactant lipids at the host-environment interface: metabolic sensors, suppressors, and effectors of inflammatory lung disease. Am J Respir Cell Mol Biol 2016; 54: 624-635.

303 Bredberg A, Gobom J, Almstrand AC, et al. Exhaled endogenous particles contain lung proteins. Clin Chem 2012; 58: 431-440.

304 Larsson P, Mirgorodskaya E, Samuelsson L, et al. Surfactant protein A and albumin in particles in exhaled air. Resp Med 2012; 106: 197-204.

305 Lärstad M, Almstrand A-C, Larsson P, et al. Surfactant protein A in exhaled endogenous particles is decreased in chronic obstructive pulmonary disease (COPD) patients: a pilot study. PLoS One 2015; 10: e0144463.

306 McKenzie JH, McDevitt JJ, Fabian MP, et al. Collection of aerosolized human cytokines using Teflon ${ }^{\circledR}$ filters. PLoS One 2012; 7: e35814.

307 Horvath I, de Jongste JC, eds. Exhaled Biomarkers (ERS Monograph). Sheffield, European Respiratory Society, 2010 .

308 McCulloch M, Jezierski T, Broffman M, et al. Diagnostic accuracy of caninescent detection in early- and late-stage lung and breast cancers. Integr Cancer Ther 2006; 5: 30-39.

309 Hirotsu T, Sonoda H, Uozumi T, et al. A highly accurate inclusive cancer screening test using Caenorhabditis elegans scent detection. PLoS One 2015; 10: e0118699.

310 Schott M, Klein B, Vilcinskas A. Detection of illicit drugs by trained honeybees (Apis mellifera). PLoS One 2015; 10: e0128528.

311 Rattray NJ, Hamrang Z, Trivedi DK, et al. Taking your breath away: metabolomics breathes life in to personalized medicine. Trends Biotechnol 2014; 32: 538-548.

312 Khalid TY, Saad S, Greenman J, et al. Volatiles from oral anaerobes confounding breath biomarker discovery. J Breath Res 2013; 7: 017114

313 Seesaard T, Lorwongtragool P, Kerdcharoen T. Development of fabric-based chemical gas sensors for use as wearable electronic noses. Sensors (Basel) 2015; 15: 1885-1902. 